\title{
Coastal Wind and Turbulence Observations during the Morning and Evening Transitions over Tropical Terrain
}

\author{
DEREK D. JENSEN \\ Lawrence Livermore National Laboratory, Livermore, California \\ TIMOThy A. PRICE \\ Department of Mechanical Engineering, University of Utah, Salt Lake City, Utah \\ DANIEL F. NADEAU \\ Department of Civil and Water Engineering, Université Laval, Quebec City, Quebec, Canada \\ JACOB KINGSTON \\ Washakie Renewable Energy, Salt Lake City, Utah \\ ERIC R. PARDYJAK \\ Department of Mechanical Engineering, University of Utah, Salt Lake City, Utah
}

(Manuscript received 22 March 2017, in final form 31 July 2017)

\begin{abstract}
Data collected during a multiyear, wind-resource assessment over a multi-land-use coastal environment in Belize are used to study the development and decay of wind and turbulence through the morning and evening transitions. Observations were made on three tall masts, forming an inland transect of approximately $5 \mathrm{~km}$. The wind distribution is found to be bimodal and governed by synoptic scales, with onshore and offshore flow regimes. The behavior between the coastal and inland sites is found to be very similar when the flow is directed offshore; for onshore flow, stark differences occur. The mean wind speed at the coastal site is approximately $20 \%$ greater than the most inland site and is nearly constant throughout the diurnal cycle. For both flow regimes, the influence of the land-sea breeze circulation is inconsequential relative to the large-scale synoptic forcing. Composite time series are used to study the evolution of sensible heat flux and turbulence kinetic energy (TKE) throughout the morning and evening transitions. The TKE budget reveals that at the coastal site mechanical production of TKE is much more important than buoyant production. This allows for the unexpected case in which TKE increases through the ET despite the decrease of buoyant TKE production. Multiresolution flux decomposition is used to further study this phenomenon as well as the evolution of the sensible heat flux at differing time scales. An idealized schematic is presented to illustrate the timing and structure of the morning and evening transitions for an inland site and a coastal site that are subjected to similar synoptic forcing.
\end{abstract}

\section{Introduction}

Morning and evening transition processes are typically marked by stark changes in the state of the atmospheric boundary layer. For example, during nighttime hours over land with clear skies, limited large-scale advection, and calm winds, the statically stable boundary layer (SBL) adjacent to the ground is characterized by weak and intermittent

Corresponding author: D. D. Jensen, jensen54@llnl.gov turbulence. Immediately above the SBL, a statically neutral residual layer (RL) persists as a remnant of the mixed layer from the previous day. Just after sunrise, surface heating begins to erode the SBL, eventually recoupling the RL with the ground, which in turn leads to the rapid development of the daytime convective boundary layer (Stull 1988). The several-hour period over which this transition occurs is the morning transition (MT). Similarly, the evening transition (ET) is a several-hour period around sunset when surface heating diminishes and the convective boundary layer 
(CBL) decays, while a near-surface SBL forms with an overlying RL (Lothon et al. 2014). The daytime CBL and nighttime SBL have been extensively studied and successfully modeled for a range of conditions [see Holtslag et al. (2013) and Steeneveld (2014) for a review]. However, accurate modeling of the MT and ET has been much more problematic (Lothon et al. 2014). The processes are inherently transient, daytime scaling laws are invalid (BlayCarreras et al. 2014; Jensen et al. 2016), turbulence develops/decays anisotropically (e.g., Nieuwstadt and Brost 1986; Pino et al. 2006; Lampert et al. 2016), the influence of surface heterogeneities is magnified (e.g., Acevedo and Fitzjarrald 2001; Cuxart et al. 2016), and the background state of the atmosphere evolves rapidly. For example, through the MT, Lenschow et al. (1979) observed temperature and wind speed changes of $12 \mathrm{~K}$ and $6 \mathrm{~m} \mathrm{~s}^{-1}$ in less than $30 \mathrm{~min}$.

Because of such complications, only recently have researchers begun studying the ET and MT intensively. Such studies are of both fundamental and pragmatic importance because the conditions near the end of the ET and MT serve as the initial condition for prognostic models of the CBL and SBL, respectively (Angevine et al. 2001). Similarly, a more complete understanding of micrometeorological phenomena that occur along the coast is also critical because the coastal transition can be treated as a boundary condition between the sea and land surfaces. In addition, an accurate understanding of coastal fluid dynamics is especially important for coastal air quality and wind energy applications (Garratt 1994; Roth 2007; Crosman and Horel 2010).

Studies of the ET have been performed numerically and observationally. In general, the objective is to understand how the near-surface atmosphere responds to the reduction of surface heating. Computational work began with the large-eddy simulations (LES) of Nieuwstadt and Brost (1986), who modeled the decay of convective turbulence when surface heating is cut off abruptly. Since then, modeling efforts have evolved to include more realistic time scales and forcing (e.g., Sorbjan 1997; Pino et al. 2006; Goulart et al. 2011; Rizza et al. 2013). In recent years, several large field campaigns have been conducted to study the decay of convective turbulence through the ET (e.g., Grant 1997; Acevedo and Fitzjarrald 2001; Brazel et al. 2005; Lothon et al. 2014; Fernando et al. 2015). BlayCarreras et al. (2014) and Jensen et al. (2016) used tower data collected during the Boundary-Layer Late Afternoon and Sunset Turbulence (BLLAST) and Mountain Terrain Atmospheric Modeling and Observations (MATERHORN) field programs, respectively, to study near-surface countergradient heat fluxes through the ET. Jensen et al. (2016) found that the duration of the countergradient heat flux is proportional to the ratio of the buoyant to gradient production terms in the sensible heat flux tendency equation. Nadeau et al. (2011) used data from the Lindenberg Inhomogeneous Terrain-Fluxes between Atmosphere and Surface: A Long-Term Study 2003 (LITFASS-2003) field campaign to successfully model the decay of turbulence through the ET using only the surface buoyancy fluctuations and turbulence dissipation. Later, Nilsson et al. (2016a) used data from the BLLAST field campaign to make detailed observations of the turbulence kinetic energy budget through the ET. Nilsson et al. (2016b) built on this work by developing a simple model to estimate the terms of the TKE budget as a function of height. The model takes the boundary layer depth, nearsurface wind speed, and surface buoyancy flux as inputs.

Until somewhat recently, most studies of the MT focused on the rapid-growth phase of the CBL (Angevine et al. 2001). For example, Bange et al. (2007) used helicopter probe measurements to study the rapid evolution of the shallow convective boundary layer (SCBL). They found that entrainment is the most important mechanism for SCBL growth. Sorbjan (2007) used LES beginning after the erosion of the SBL to evaluate similarity relations in the mixed layer with reasonable success. Angevine et al. (2001) used observational data to study the full MT, including the erosion of the SBL early in the MT. They observed that surface heating is responsible for relaxing surface stability but that most of the warming in the near-surface air mass is due to sheardriven entrainment. Similarly, the 6-yr dataset analyzed by Lapworth (2006) confirms that through the MT, nearly all warming in the surface layer is due to turbulent diffusion from above. Beare (2008) also confirmed this finding numerically by using a combination of grid sizes to run an LES study of the full evolution of the MT. In the study, the mixed CBL-SBL state, consisting of a near-surface convective layer capped by a shear-driven stable layer, is resolved. Shear production is found to be the dominant source of turbulence production throughout the MT.

Only a small number of studies have examined both the ET and MT in a single study. In all cases that we are aware of, the studies have focused on the diurnal cycle, rather than processes unique to the MT and ET. Several studies have successfully modeled a full diurnal cycle using LES (e.g., Wang et al. 1998; Kumar et al. 2006; Basu et al. 2008; Rizza et al. 2013), and others have studied the diurnal cycle utilizing mesoscale models (e.g., Zhang et al. 2004; Svensson et al. 2011).

Here, we study processes specific to the MT and ET using an extensive 30 -month dataset collected over a coastal tropical site. Along the coast, the mean wind may be directed alongshore or cross-shore (onshore/ offshore). In the onshore and offshore cases, an internal boundary layer (IBL) develops as the air mass near the surface adapts to the changing surface conditions [see Garratt (1990) and Angevine (2008) for 


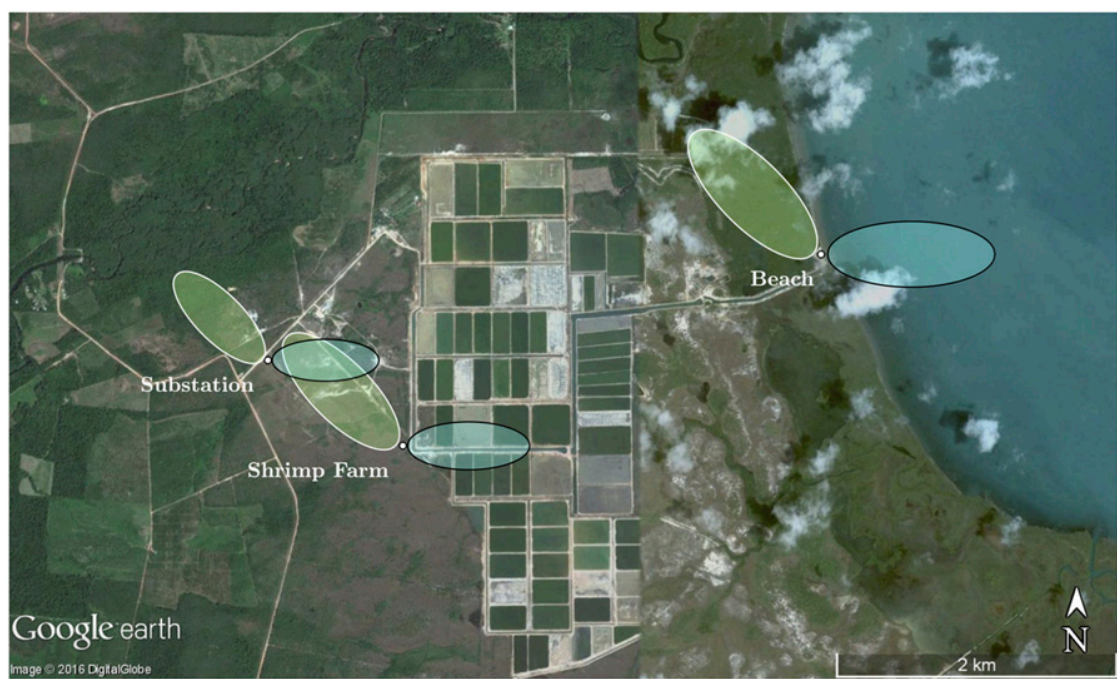

FIG. 1. Map of the study area; patches in the center of the image are shrimp ponds that are approximately $1.5 \mathrm{~m}$ in depth. The translucent ellipses represent the approximate onshore (blue) and offshore (green) flux footprints calculated at a height of $10 \mathrm{~m}$ for weakly unstable conditions using Eq. (1) (see section 3a).

reviews]. In the canonical case of daytime onshore flow, the surface transitions from the smooth, cool ocean to the rough, warm land. The flow decelerates and turbulence increases, and the deepening of the IBL is roughly proportional to the square root of the inland distance, depending on stability and surface roughness (Garratt 1990). For the offshore case, the flow accelerates and turbulence decays proportional to the drop in surface roughness between the land and the sea. The study of Parameswaran et al. (1997) used data collected at a tropical, coastal station to study the influence of the coastal transition on aerosol concentrations through the ET. They found that the maximum concentrations occurs early in the night and slowly decrease thereafter. Similarly, Manoj et al. (2013) used lidar data collected over a tropical, urban site in India to relate the development of low-level stratiform clouds to aerosol concentrations. We are unaware of any studies that investigate the MT and ET over coastal, tropical terrain.

The objective of the current study is to build upon previous micrometeorological work of the MT, ET, and coastal boundary layer to yield a more complete understanding of turbulence characteristics during such conditions. Data for the study were collected on three tall masts at a coastal site over heterogeneous terrain in Belize. The structure of the results and discussion (section 3) is as follows: First, the wind climatology of the region is discussed; both temporal [section 3a(1)] and spatial patterns [section 3a(2)] are identified. The surrounding discussion is relevant to wind energy production and also as a necessary step toward studying the MT and ET. Next, the evolution of sensible heat flux and the evolution of turbulence kinetic energy through the morning and evening transitions are treated in sections $3 b(1)$ and $3 b(2)$, respectively. Finally, an idealized schematic of the timing and turbulence structure through the MT and ET is presented in section $3 b(3)$.

\section{Methods}

Data for the study were collected as part of a windresource assessment over a shrimp farm in Stann Creek, Belize. Data collection began on 1 December 2013 and concluded on 25 April 2016.

\section{a. Study area}

Three experimental sites are examined in the study. The Beach $\left(17^{\circ} 5^{\prime} 8.5^{\prime \prime} \mathrm{N}, 88^{\circ} 17^{\prime} 12.1^{\prime \prime} \mathrm{W}\right)$, Shrimp Farm $\left(17^{\circ} 4^{\prime} 22.6^{\prime \prime} \mathrm{N}, 88^{\circ} 18^{\prime} 55.2^{\prime \prime} \mathrm{W}\right)$, and Substation $\left(17^{\circ} 4^{\prime} 43.0^{\prime \prime} \mathrm{N}\right.$, $88^{\circ} 19^{\prime} 26.5^{\prime \prime} \mathrm{W}$ ) sites form an approximate inland transect between 0 and $5 \mathrm{~km}$. Figure 1 gives the location of the sites, and site photographs are shown in Fig. 2. Elevation change between the sites is minimal, with approximate elevations of 2, 9, and $20 \mathrm{~m}$ at Beach, Shrimp Farm, and Substation, respectively. Discussion of site heterogeneity and tower fetches is found in section 3a1. At the Beach site, a threerow windbreak of palm trees exists between the Beach tower and the ocean (Fig. 2d). The break is approximately $15 \mathrm{~m}$ wide and begins $35 \mathrm{~m}$ to the east of the Beach tower. The height of the canopy base is approximately $2 \mathrm{~m}$, and the height of the top of the canopy is approximately $6 \mathrm{~m}$. 


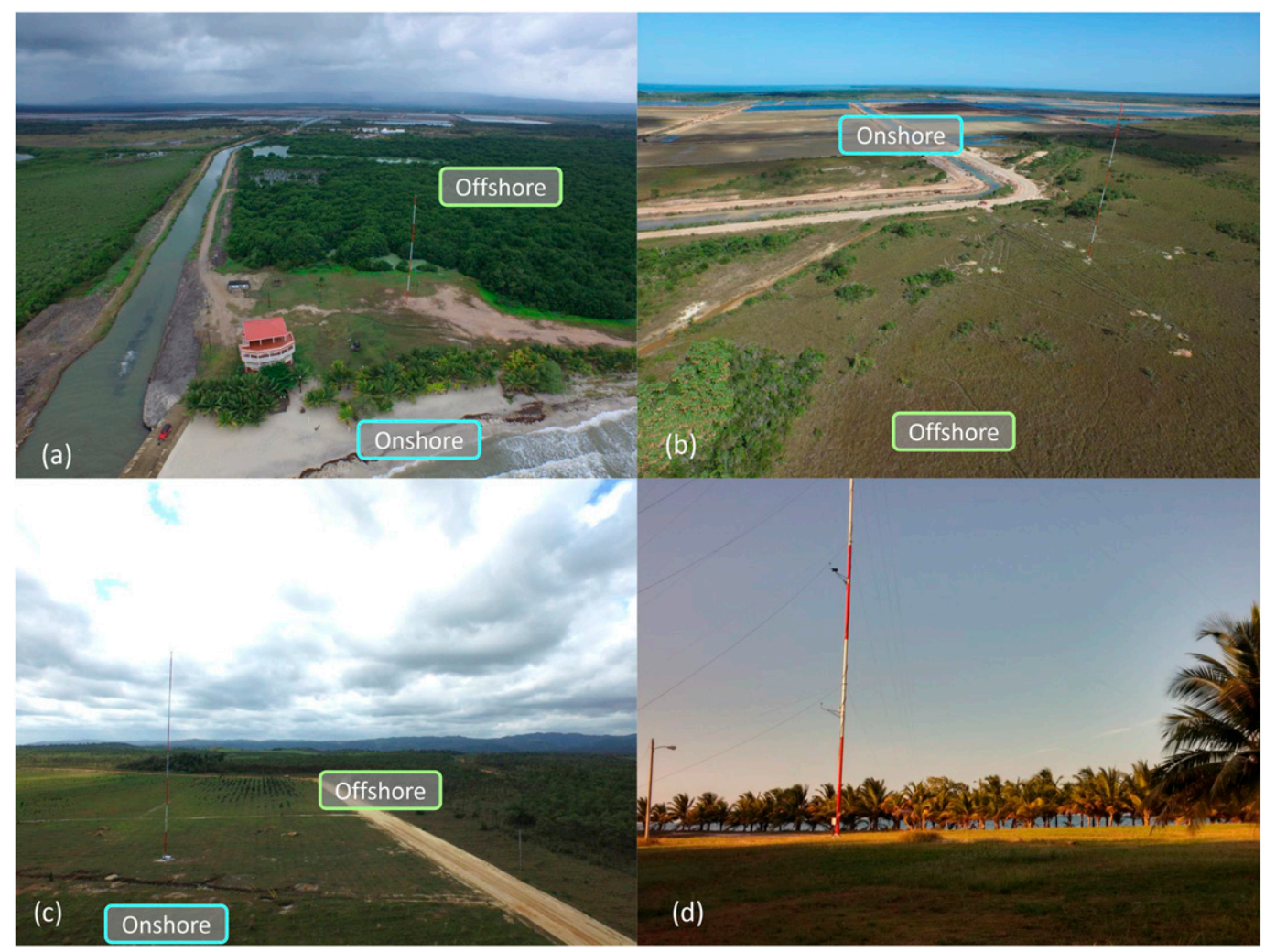

FIG. 2. Photographs of the (a) Beach, (b) Shrimp Farm, and (c) Substation sites with the approximate onshore and offshore fetches indicated (see section 3a). (d) The alongshore windbreak at the Beach site.

\section{b. Instrumentation and data analysis}

Mean variables were sampled at multiple levels at all sites and sonic anemometers were used to measure turbulence at the Beach and Substation sites. Figure 3 illustrates the instrumentation at each site and Table 1 gives instrument details. Each tower level was instrumented with redundant anemometers. All mean wind speeds were taken from the cup anemometers. Mean variables were sampled at $1 \mathrm{~Hz}$; turbulence was initially sampled at $20 \mathrm{~Hz}$ and subsequently dropped to $10 \mathrm{~Hz}$ to improve logger stability (i.e., the scan rate was dropped to decrease the number of skipped scans and spurious measurements that we observed to increase when the logger was left unattended for long periods).

Data were stored locally on Campbell Scientific, Inc., dataloggers, and 10-min-averaged data were transmitted via cellular modems nightly. Because of the remoteness of the site, instrumentation problems could not always be corrected immediately, and therefore data availability diminished slightly through the experiment.

Data were analyzed with the Utah Turbulence in Environmental Studies processing and analysis code (UTESpac; Jensen et al. 2016). A multisector planar fit and subsequent yaw rotation was applied to the sonic- anemometer data to align the sonic-anemometer coordinate system with the mean wind field. The quantity $u$ is the longitudinal velocity component, $v$ is the transverse, and $w$ is the vertical. Given that the emphasis of the study is on the MT and ET, where conditions evolve rapidly, 10-min averaging periods were used to compute both the mean variables and higher-order moments. Later in section 3b1, we show that $10 \mathrm{~min}$ is sufficient to capture the majority of the turbulent flux while omitting larger-scale fluctuations associated with the meso- and synoptic scales.

\section{c. Composite time series methodology}

To better utilize the large dataset, composite time series were constructed to give a climatological sense of the flow characteristics. Throughout the data analysis, many individual days were compared with the composited results to ensure that the composites were representative of their population. For the study, the composite time series were constructed following two methodologies.

First, for treatment of the full diurnal cycle in section 3a, the composite time series were constructed by aligning the individual days from midnight to midnight 


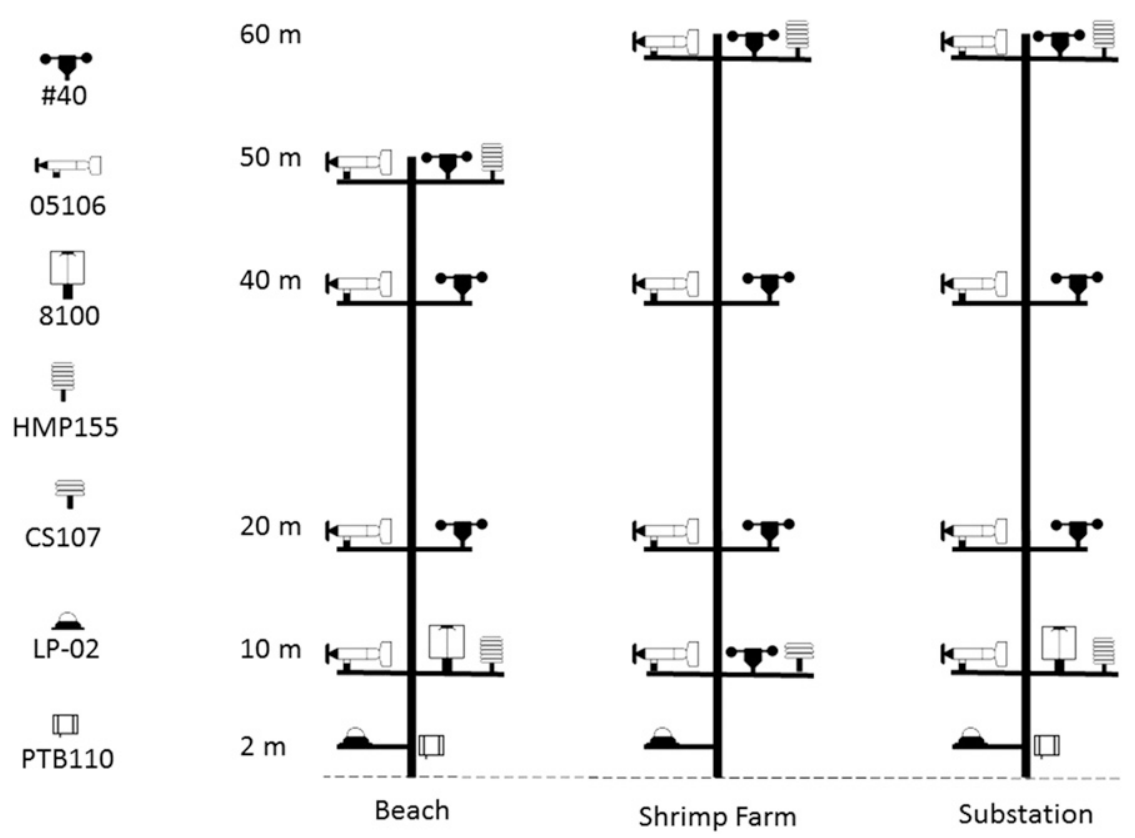

FIG. 3. Instrumentation deployed at the three sites. See Table 1 for instrument details.

and simply taking their mean values. Second, to examine the morning and evening transition in section $3 \mathrm{~b}$, time relative to sunrise $\left(\tau_{\text {sunrise }}\right)$ and sunset $\left(\tau_{\text {sunset }}\right)$ was used to align the data. The time of sunrise and sunset was calculated with a threshold of $5 \mathrm{Wm}^{-2}$. To limit noise in the calculations, the observed transition times were then smoothed using the smooth.m function in MATLAB with the "rloess" option. A simple solar model was also tested but was unable to account for diffuse effects that apparently vary seasonally. Sunrise and sunset were assumed to be constant at all three sites and the transition times, $\tau_{\text {sunrise }}$ and $\tau_{\text {sunset }}$, were taken from the smoothed signals. Because Belize is in the tropics $\left(17^{\circ} \mathrm{N}\right)$, the annual variation in sunrise and sunset is less than it is at sites in the midlatitudes. Several other methodologies and thresholds were tested to estimate the local sunrise and sunsets, but the combination of the $5 \mathrm{~W} \mathrm{~m}^{-2}$ threshold with the interdiurnal smoothing appeared to yield the most accurate results.

\section{d. Multiresolution flux decomposition}

In section $3 \mathrm{~b}$, multiresolution flux decomposition (MRFD) is used to study the evolution of sensible heat flux and TKE at different temporal scales. MRFD is a tool that is similar to Fourier decomposition but has the advantage of satisfying Reynolds averaging at all scales and does not assume periodicity (Howell and Mahrt 1997). MRFD is implemented by decomposing the signal into simple averages computed over different time scales and represents the simplest possible orthogonal decomposition (see Vickers and Mahrt 2003). Similar to

TABLE 1. Instrumentation deployed during the 30-month field campaign. See Fig. 3 for instrument locations. Here, WS is wind speed; $u, v$, and $w$ are the longitudinal, transverse, and vertical wind speeds, respectively; $T_{s}$ is the sonic-derived temperature and is approximately equal to virtual temperature; $T$ is air temperature; RH is relative humidity; $R_{S} \downarrow$ is incoming global shortwave radiation; and $P$ is pressure.

\begin{tabular}{lccc}
\hline \hline Instrument name & Variables measured & Accuracy & Manufacturer \\
\hline NRG No. 40 & WS & $\pm 0.15 \mathrm{~m} \mathrm{~s}^{-1}$ & NRG Systems \\
RMY05106 & $\mathrm{WS}$ & $\pm 0.3 \mathrm{~m} \mathrm{~s}^{-1}$ & R. M. Young \\
RMY8100 & $u, v, w$ & $\pm 0.05 \mathrm{~m} \mathrm{~s}^{-1}$ & R. M. Young \\
& $T_{s}$ & $\pm 2^{\circ} \mathrm{C}$ & Vaisala \\
HMP155 & $T$ & $\pm 0.2^{\circ} \mathrm{C}$ & Campbell Scientific \\
& $\mathrm{RH}$ & $\pm 1 \%$ & Huskeflux \\
CS107 & $T$ & $\pm 0.4^{\circ} \mathrm{C}$ & Vaisala \\
LP-02 & $R_{S} \downarrow$ & $\pm 10 \%$ day & $\pm 0.6 \mathrm{hPa}^{-1}$ \\
PTB110 & $P$ & \pm
\end{tabular}




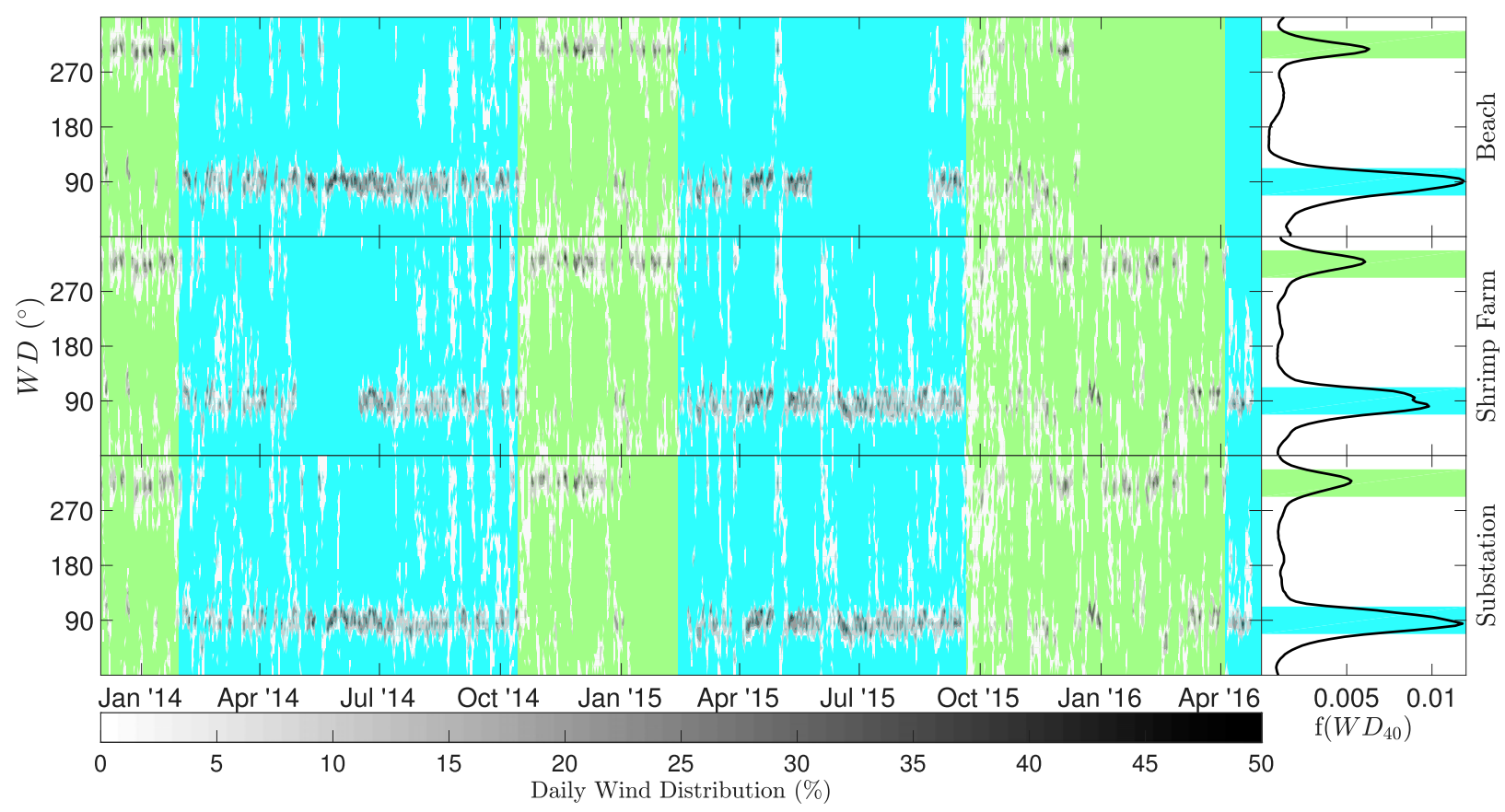

FIG. 4. (left) Wind-direction contours. The onshore and offshore seasonal regimes are indicated by the blue and green shading, respectively. Gaps in the time series indicate periods with instrument malfunctions. (right) The 40-m wind-direction probability density functions. Blue shading indicates the onshore flow regime $\left(90^{\circ} \pm 22.5^{\circ}\right)$, and green indicates the offshore flow regime $\left(315^{\circ} \pm 22.5^{\circ}\right)$.

Fourier spectra, MRFD can be used to show the time scales that contribute to the variance of the signal. Vickers and Mahrt (2003) used MRFD to determine the proper flux averaging period by identifying the cospectral gap between turbulence fluctuations and mesoscale motions. Katul and Parlange (1995) used MRFD to study the structure of turbulence at production wavenumbers.

Here, we use MRFD to study the structure of turbulence through the MT and ET at the Beach and Substation sites. We follow the methodology described in Vickers and Mahrt (2003), where the multiresolution spectra are interpreted in terms of a simple, unweighted moving averages. MRFD works by splitting the time series into simple averages over different scales. First, the average over the entire record is calculated and subsequently subtracted. The average departure from the mean is then recorded. Next, the averaging period is broken into two subperiods, over which the respective means are computed and subsequently removed. The subperiods are divided again, and the process is repeated until there is only one sample per averaging period (see Vickers and Mahrt 2003, their Fig. 1). With each step, the data are high-pass filtered with the filter width becoming progressively more narrow. The departures from each period are then used to compute the spectra and cospectra with Eqs. (2) and (3) in Vickers and Mahrt (2003).

\section{Results and discussion}

\section{a. Flow climatology}

\section{1) TEMPORAL WIND PATTERNS}

The prevailing wind directions were identified using their probability density function (right side of Fig. 4). The distributions are strongly bimodal, with the predominant wind regimes being easterly onshore and northwesterly offshore.

Contours of the time series of 40-m wind direction are also shown in Fig. 4. The contours illustrate that the bimodal flow regime is seasonal, rather than diurnal, as might be expected for thermally driven sea breezes (see Stull 1988, section 14.1.2). The observed wind regimes are consistent with those typical of the region (National Meteorological Service of Belize 2016). The onshore regime occurs mostly during the rainy season (April-October) and the offshore regime occurs primarily during the dry season (NovemberMarch). Although the actual mechanisms driving the flow are more complicated (Sáenz and DuránQuesada 2015), the onshore flow and precipitation are predominantly driven by tropical waves, tropical storms, and hurricanes that move westward through the Caribbean Sea. The offshore flow is produced by cold fronts that move southeast across the continental United States. On average, a cold front passes over 
TABLE 2. Flow-regime characterization at the three sites for onshore $\left(90^{\circ} \pm 22.5^{\circ}\right)$ and offshore $\left(315^{\circ} \pm 22.5^{\circ}\right)$ flow. The value of $z_{0}$ is estimated from Fig. 9.6 in Stull (1988), $\bar{T}(\overline{\mathrm{RH}})$ is the mean temperature (relative humidity), and $\sigma_{\bar{T}}\left(\sigma_{\overline{\mathrm{RH}}}\right)$ is the standard deviation of the 10-min temperature (relative humidity).

\begin{tabular}{|c|c|c|c|c|c|c|c|c|c|c|}
\hline & \multicolumn{5}{|c|}{ Onshore regime } & \multicolumn{5}{|c|}{ Offshore regime } \\
\hline & $\begin{array}{c}\text { No. of } \\
\text { days }\end{array}$ & Fetch & $\begin{array}{c}z_{0} \\
(\mathrm{~m})\end{array}$ & $\begin{array}{c}\bar{T}\left(\sigma_{\bar{T}}\right) \\
\left({ }^{\circ} \mathrm{C}\right)\end{array}$ & $\begin{array}{c}\overline{\mathrm{RH}}\left(\sigma_{\overline{\mathrm{RH}}}\right) \\
(\%)\end{array}$ & $\begin{array}{c}\text { No. of } \\
\text { days }\end{array}$ & Fetch & $\begin{array}{c}z_{0} \\
(\mathrm{~m})\end{array}$ & $\begin{array}{c}\bar{T}\left(\sigma_{\bar{T}}\right) \\
\left({ }^{\circ} \mathrm{C}\right)\end{array}$ & $\begin{array}{c}\overline{\mathrm{RH}}\left(\sigma_{\overline{\mathrm{RH}}}\right) \\
(\%)\end{array}$ \\
\hline Beach & 225 & Ocean & $10^{-3}$ & $28.3(1.2)$ & 79 (4) & 48 & Mangrove & 0.4 & $22.8(2.2)$ & $86(10)$ \\
\hline Shrimp Farm & 228 & $\begin{array}{l}\text { Shrimp } \\
\text { ponds }\end{array}$ & 0.03 & $28.1(1.3)$ & - & 70 & $\begin{array}{l}\text { Grassland/ } \\
\text { tropical forest }\end{array}$ & 0.5 & $23.0(2.5)$ & - \\
\hline Substation & 238 & Grassland & 0.08 & $28.0(1.3)$ & $79(6)$ & 61 & Tropical forest & 0.8 & $22.7(2.5)$ & $84(11)$ \\
\hline
\end{tabular}

Belize about once every 10 days through the dry season (National Meteorological Service of Belize 2016). The variability in the arrival of the cold fronts leads to more variability in wind direction through the dry season (Fig. 4).

Given that the flow regimes are predominantly seasonal, rather than diurnal, days can be characterized by the mode of the 40-m wind direction. The daily wind mode is computed by sorting the wind direction into bins with widths of $10^{\circ}$. In general, the daily wind mode is a very good indicator of the predominant wind direction for a given day.

Table 2 describes the two flow regimes. Days were sorted into the two flow regimes using two criteria. First, the daily wind mode had to fall within either the onshore $\left(90^{\circ} \pm 22.5^{\circ}\right)$ or offshore $\left(315^{\circ} \pm 22.5^{\circ}\right)$ wind-direction envelope. Second, more than two-thirds of the 10-min observations had to fall within the respective envelope. Days that did not meet both of these criteria were omitted from the study. We are left with well over 200 days of onshore flow at all sites and over 45 days of offshore flow at all sites. This allows us to composite a large amount of data to allow for a more climatological analysis of the two flow regimes, rather than studying isolated events.

As illustrated in Figs. 1 and 2, the three sites are situated approximately at land cover transition zones, and therefore the upwind fetches vary between wind regimes. At the Beach site, the tower sits roughly $70 \mathrm{~m}$ from the ocean shore, with a windbreak positioned parallel to the beach and between the shore and tower (see section 2a). The offshore regime consists predominantly of mangrove forest that is approximately 5-m tall. At the Shrimp Farm site, the onshore fetch is over shrimp ponds that are approximately $1.5 \mathrm{~m}$ in depth. All ponds have a north-south dimension of approximately $300 \mathrm{~m}$ and an east-west dimension of either 150 or $300 \mathrm{~m}$ (Fig. 1). The offshore fetch at Shrimp Farm is predominantly tropical grassland with presumably some influence from tropical forests located farther upstream. Finally, the Substation site is located over an immature grove of mahogany trees. Although it was not explicitly measured, from photographs it appears that the height of the trees did not change substantially over the experiment, with small saplings near the tower base and trees between 3 and $5 \mathrm{~m}$ tall approximately $100 \mathrm{~m}$ to the west of the tower (Fig. 2c). Beyond the grove, the offshore fetch is predominantly tropical forest with hills approximately $8 \mathrm{~km}$ to west of the tower. Finally, the onshore fetch is mostly tropical grassland with shrimp ponds and the ocean upstream.

Because of the heterogeneous topography at each site, it is difficult to accurately estimate the surface roughness $\left(z_{0}\right)$ and zero-plane displacement using both profile methods (Robinson 1962) and single-level sonic-anemometer estimates (Graf et al. 2014). Instead, the surface roughness was estimated as a best guess, using a combination of the profile method and Fig. 9.6 in Stull (1988). Though this leads to uncertainty in the estimate of $z_{0}$, the parameter is only used in this study to calculate the approximate flux footprints at each site. Therefore, the added uncertainty is tolerated.

The flux footprints for both wind regimes at all three sites are indicated by shaded ellipses in Fig. 1. Their minor axes are equivalent to the width of the wind envelope $\left(45^{\circ}\right)$, and their major axes $x_{\mathrm{FP}}$ are estimated following Hsieh et al. (2000) as

$$
x_{\mathrm{FP}}=\frac{D z_{u}^{p}|L|^{1-p}}{\kappa^{2} \ln \left(F^{*}\right)},
$$

where $D$ and $p$ are stability-dependent constants taken as suggested in Hsieh et al. (2000); $z_{u}=z_{m} \ln \left(z_{m} / z_{0}\right)$ $-1+z_{0} / z_{m}$ is a combined length scale where $z_{m}$ is the measurement height; $\kappa=0.4$ is the von Kármán constant; and $F^{*}$, taken here as 0.9 , is the fraction of the total flux generated between the tower base and an upwind distance of $x_{\mathrm{FP}}$. The Obukhov length is calculated as

$$
L=\frac{-\overline{\theta_{v}} u_{*}^{3}}{\kappa g \overline{w^{\prime} \theta_{v}^{\prime}}},
$$

where $\theta_{v}$ is the virtual potential temperature, estimated here by the sonic-derived air temperature $\theta_{s}, u_{*}$ is the friction velocity, and $g$ is gravitational acceleration. 


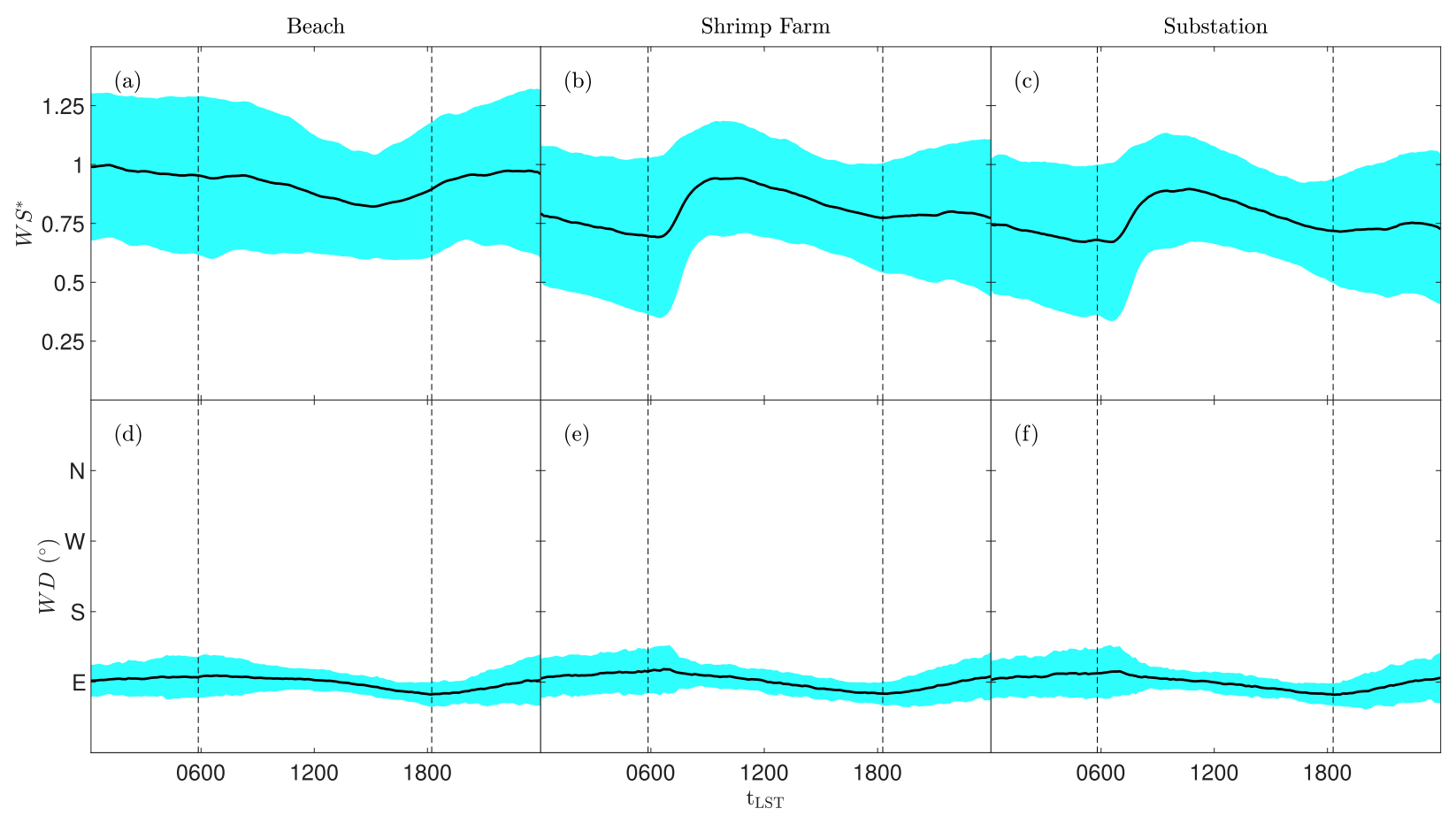

FIG. 5. The 40-m composite (top) wind speed and (bottom) wind-direction time series for the onshore flow regime at (a),(d) Beach, (b), (e) Shrimp Farm, and (c),(f) Substation. Note that the wind speed (WS*) is the wind speed normalized by the maximum observed velocity in either regime and all sites; this occurs in the onshore regime at Beach. The shading illustrates \pm 1 std dev from the mean, and the mean time of sunrise and sunset for the onshore flow regime is indicated by the vertical lines.

Qualitatively, the magnitude of $L$ indicates the depth over which shear production of turbulence is important (Stull 1988).

The flux footprints were estimated at $10 \mathrm{~m}$ (the level of the sonic anemometers) under slightly unstable conditions typical at the beginning of the ET or end of the MT. For higher tower levels or stable conditions, the flux footprint becomes much larger. Nonetheless, the calculated footprints show the general area of upwind fetch for each flow regime at each tower.

\section{2) SPATIAL WIND PATTERNS}

Composite time series of the normalized wind speed and wind direction for the onshore and offshore flow regimes are shown in Figs. 5 and 6, respectively. The wind speed is normalized by the maximum wind speed in the composite time series for both wind regimes and at all sites. The maximum occurs at the Beach site for the onshore regime. The normalization is performed in order to not disclose the wind resource and also to visualize the inland wind speed deficit.

In general, the onshore wind regime is associated with higher wind speeds. At the Beach site, the offshore winds are typically $<80 \%$ of the onshore values. In both cases, the diurnal range of the Beach wind speed is quite small relative to the other sites. At the Shrimp Farm and
Substation sites, the difference in the mean wind speed is less between the two flow regimes. For both regimes, daytime hours are associated with higher wind speeds. This is likely due to increased mixing that more effectively couples the 40-m air layer with the faster-moving air aloft. Later in the afternoon as mixing decreases, the coupling weakens, and the 40-m wind speed decreases. An inland wind speed deficit occurs during the onshore flow regime. Taking the mean velocity at each site and using a linear fit, the inland wind speed deficit is estimated to be approximately $4 \% \mathrm{~km}^{-1}$. As expected, the inland wind speed deficit for offshore flow regime is $<1 \% \mathrm{~km}^{-1}$. For wind energy production, the benefit of constructing turbines on or near the coast is clear. The mean wind speeds are highest for both flow regimes and the diurnal wind speed range is relatively small, allowing for a more reliable energy source.

Next, the sea breeze, inferred by the horizontal temperature difference $\Delta T / \Delta x$, is considered. For typical sea breeze circulations, surface heating warms the inland air mass causing it to rise; the cool air over the body of water then flows inland because of the horizontal pressure gradient generated by the rising inland air mass. During the night, the opposite occurs and the cooler inland air mass flows toward the warmer body of water (Stull 1988; Crosman and Horel 2010). Figure 7 illustrates the 


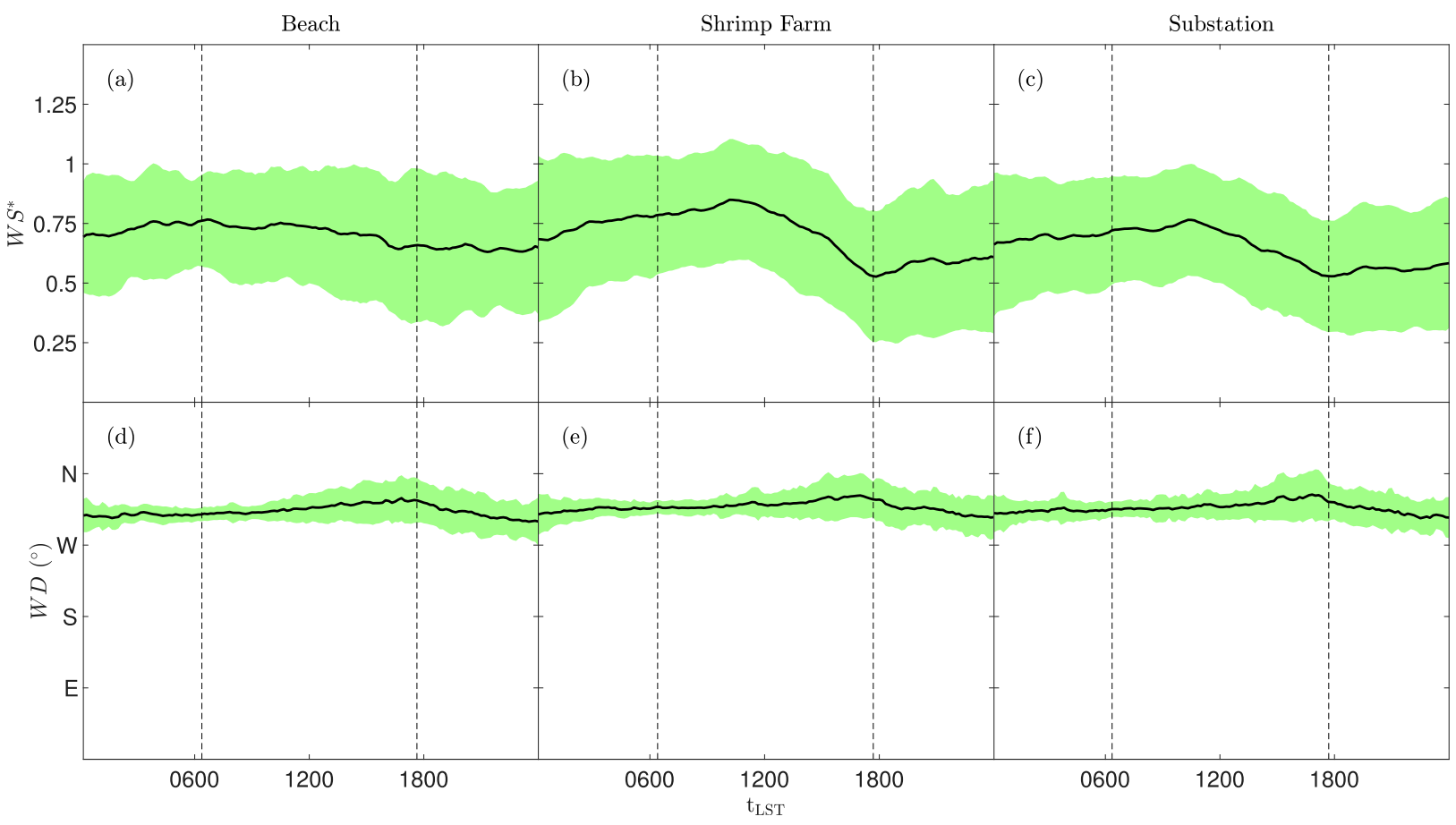

FIG. 6. As in Fig. 5, but for the offshore flow regime.

horizontal temperature gradients responsible for driving the sea-land breeze circulation over the shrimp farm. It is possible that for the onshore regime, the existence of a diurnal land-sea breeze could be partially responsible for the observed acceleration during daylight hours. However, if this were the case, an acceleration at the Beach site would also be expected. Therefore, if a landsea breeze is present at the site, we conclude that its magnitude is insufficient to have an appreciable impact on the observed 40-m wind speed. Nonetheless, Fig. 7 illustrates the interaction between the inland temperature gradient and the prevailing synoptic forcing. Of particular interest is the differing behavior of the crossover and magnitude of $\Delta T / \Delta x$ between the two flow regimes. In general, the magnitude of the gradient is much larger for onshore flow. It is not until more than $2 \mathrm{~h}$ after sunrise that the inland temperature gradient becomes positive and it becomes negative again more than $2 \mathrm{~h}$ before sunset. For the offshore case, the magnitude of $\Delta T / \Delta x$ is significantly lower. However, unlike the onshore case, the crossover points of the inland temperature gradient occur near sunrise and sunset. The differing behavior between the two flow regimes is related to the sensor footprints. For onshore flow, the Beach footprint is over the ocean, which behaves much like a constant-temperature thermal reservoir; for the offshore case, the footprint is over mangrove swamps. The mangrove swamps are closer to being in equilibrium with the land and thus create weaker gradients that cross over much nearer to the change in solar forcing.

\section{$b$. The morning and evening transitions}

In this section, the mean behavior through the MT and ET is considered with composite time series of turbulence variables. Since sonic anemometers were only deployed at the 10-m level at Beach and Substation, there is no discussion of the Shrimp Farm site. However, based on similarities between Shrimp Farm and Substation in the previous section, we use the Beach site observations to characterize the coastal evolution and Substation to characterize the inland evolution.

\section{1) Heat flux evolution}

The sensible heat flux and potential temperature gradient in Fig. 8 indicate that countergradient heat fluxes occur through the ET and MT at both sites. Nearsurface countergradient heat fluxes through the ET have been discussed previously in Blay-Carreras et al. (2014) and Jensen et al. (2016). Blay-Carreras et al. (2014) observed countergradient durations of 30-80 min using heat flux observations at a height of $2.23 \mathrm{~m}$ and gradient observations calculated with temperature measurements at 2.23 and $3.23 \mathrm{~m}$. The time where the sensible heat flux crosses zero was found to always precede the that of the temperature gradient. Jensen et al. (2016) studied near-surface countergradient heat fluxes at 


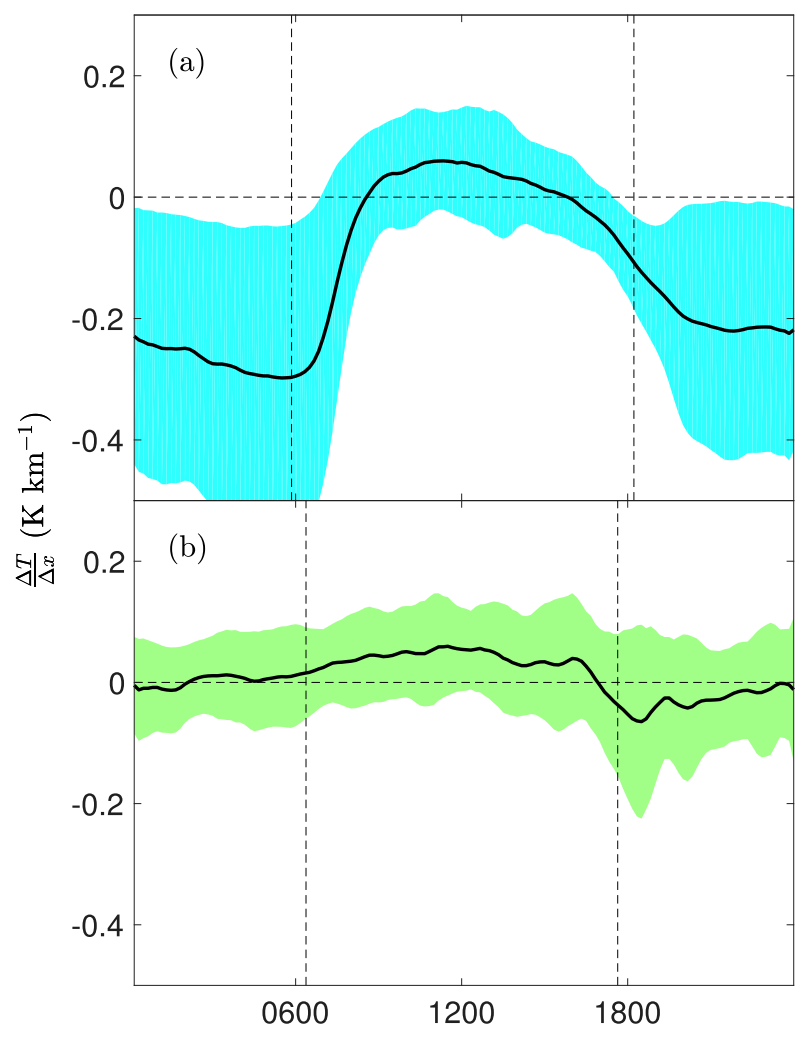

FIG. 7. Composite time series of the inland temperature gradient computed at the 10-m levels at the Beach and Substation locations using simple differencing for the (a) onshore and (b) offshore flow regimes. Positive (negative) gradients indicate that the air temperature increases (decreases) with inland distance. The shading indicates the time series \pm 1 std dev.

multiple levels between 0.5 and $20 \mathrm{~m}$ at two contrasting sites. Jensen et al. (2016) observed both the sign change of sensible heat flux occurring prior to that of the temperature gradient, consistent with the observations of Blay-Carreras et al. (2014), as well as the opposite, where the temperature gradient crossover precedes the heat flux sign change. They modeled the countergradient type and countergradient duration by considering the ratio of gradient to buoyant production in the sensible heat flux budget.

At Substation and Beach through the ET, the temperature gradient is observed to crossover prior to the heat flux, opposite to what was observed by Blay-Carreras et al. (2014), though the countergradient duration at Substation for the onshore flow regime is very short. It should be noted that the situation encountered in the present study is broadly different from the observations of Blay-Carreras et al. (2014) and Jensen et al. (2016). First, the temperature gradient is computed over a vertical distance of 40 or $50 \mathrm{~m}$, creating a degree of uncertainty in the estimate of the local temperature gradient. Second, the sites considered here are characterized by heterogeneous terrain, indicating that advection is important, particularly for the onshore regime at Beach.

Nonetheless, the observations presented here build on existing literature and indicate that the use of the socalled gradient-transport theory or K-theory is poorly suited for the MT and ET. This is due to the rapid evolution of the atmosphere through such transitions, where local gradients become poor indicators of the scales that are actually responsible for transporting sensible heat. The application here is further complicated by the heterogeneous terrain and advection.

It is interesting that, at both sites and for both flow regimes, the sensible heat flux crossover precedes the gradient sign change for the MT, whereas the opposite is true through the ET. This occurs in the composite time series as well as on many individual days (not shown). This result indicates that, for a given day, the total duration of positive sensible heat flux (directed away from the surface) is longer than the total duration of the unstable temperature gradient. Based on previous work (see Jensen et al. 2016), we hypothesize that if the temperature gradient were calculated just above the surface then the countergradient duration would shrink to nearly zero. Although we are unable to validate the hypothesis, we observe that in general the countergradient duration at Substation is much shorter than at Beach. We also observe that the sensible heat flux is typically much larger at Substation, leading to stronger mixing and thus shorter countergradient durations.

Figure 9 gives composite contour plots of the sensible heat flux MRFD cospectra through the MT and ET at Beach and Substation for both flow regimes. The cospectra were calculated using $2^{16}$ data points, which equates to $\approx 55 \mathrm{~min}$ of data recorded at $20 \mathrm{~Hz}$. Note that much of the experiment was recorded at $10 \mathrm{~Hz}$ and subsequently interpolated to $20 \mathrm{~Hz}$ to yield a uniform dataset. Thus, little to no information is available beyond the effective Nyquist frequency of $5 \mathrm{~Hz}\left(10^{-0.7} \mathrm{~s}\right)$. To improve temporal resolution, the MRFD cospectra advance forward in time in increments of $2^{16} / 2$ data points, or about $27 \mathrm{~min}$. In Fig. 10, selected small, peak, and large time scales of the sensible heat flux cospectra are given as time series. The locations of the scales within the cospectra are indicated in Fig. 9. The peak scale is taken as the time scale associated with the largest-magnitude flux; the small and large time scales are taken as the points where the energy content has dropped to $50 \%$ of the peak value toward the smaller and larger scales, respectively. The time series are normalized by their maximum value to allow for an easy comparison of turbulence development and decay between time scales. 


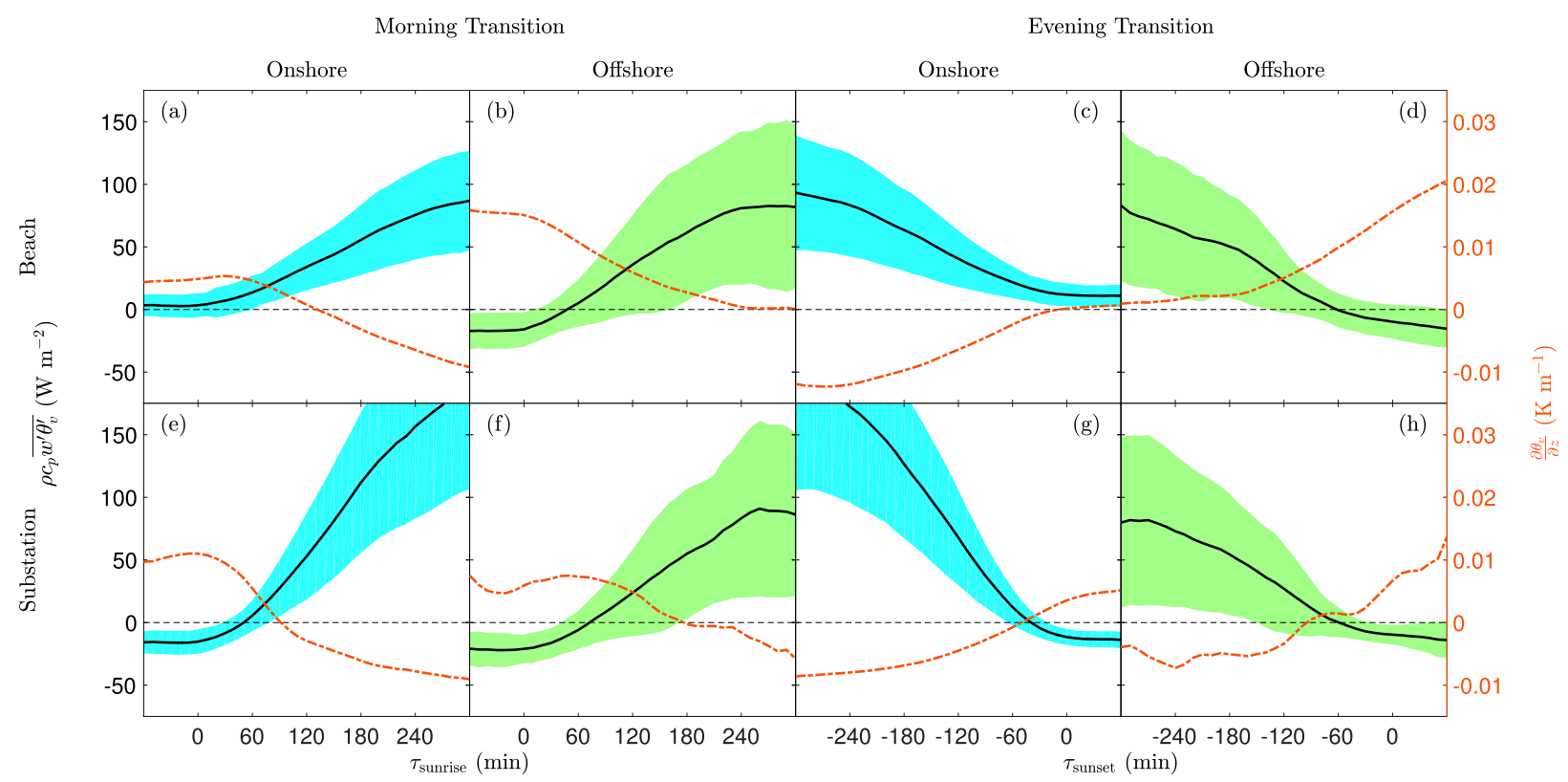

FIG. 8. Composite time series of the 10-m sensible heat flux (left $y$ axis) and potential temperature gradient (right $y$ axis) through the MT and ET for both onshore (40-m daily wind mode $\left.=90^{\circ} \pm 22.5^{\circ}\right)$ and offshore $\left(40-\mathrm{m}\right.$ daily wind mode $\left.=315^{\circ} \pm 22.5^{\circ}\right)$ flow regimes at the Beach and Substation locations. The shading indicates \pm 1 std dev of the composite sensible heat flux time series. The virtual potential temperature gradient is computed with forward differencing between the 10- and 50-m levels at Beach and between the 10- and 60-m levels at Substation.

We observe a shift in the peak time scales between the onshore and offshore regimes at the Beach site. The peak scale at the Beach site for onshore flow occurs at approximately $3 \mathrm{~s}$ and for offshore flow occurs around $12 \mathrm{~s}$ in the MT and $25 \mathrm{~s}$ in the ET. At the Substation site, the peak scale is constant through the MT and ET for both flow regimes and is approximately $25 \mathrm{~s}$. The smaller peak time scale for the onshore Beach flow is likely due to the footprint over which the flux is generated. The low surface roughness and shallow mixed layer typical over oceans (Garratt 1994) are likely responsible for the smaller peak time scale. Once the inland flow has reached the Substation site, the reduced peak time scale is no longer evident, indicating that the near-surface atmosphere has come into equilibrium with the land surface.

In general, the offshore regime shows relatively large negative heat fluxes at the beginning of the MT and end of the ET at both sites, for all but the largest scales. For the onshore regime, the heat flux is much larger at the end of the MT and beginning of the ET. This is because the onshore regime occurs during the summer months. Through the MT, the crossover from negative heat flux to positive occurs first at larger scales and then propagates to the smaller scales. For scales $\gtrsim 10^{2.5} \mathrm{~s}(\approx 5 \mathrm{~min})$, contributions to both the negative and positive sensible heat fluxes are minimal for both sites, transitions, and regimes, indicating the beginning of the cospectral gap.
As discussed in Vickers and Mahrt (2003), identification of the gap is important for appropriate determination of flux averaging times. Scales smaller than the gap are associated with local turbulence and expected to follow similarity theory relationships. Scales greater than the gap are associated with nonstationarity and meso- or synoptic-scale motions that do not adhere to similarity theory. Thus, Fig. 9 indicates that our use of a 10-min averaging period is contained within the gap and is appropriate.

Normalized, representative large, peak, and small time-scale fluctuations of the sensible heat flux are given in Fig. 10. The larger sensible heat flux that occurs during the onshore flow regime is evident at all scales. During the MT, for the offshore Beach regime and both regimes at Substation, the crossover of the sensible heat flux occurs at all scales over a period of approximately $30 \mathrm{~min}$. The large-scale flux crosses zero first, followed by the peak and then small scales (note that the zero-flux contour in Fig. 9 helps to further illustrate this). Through the ET, the crossover at Substation occurs slightly earlier at the small scales. It is interesting that at the Substation site our observations indicate that through the MT, sensible heat flux is first generated at large time scales, and through the ET, sensible heat flux decays first at the small time scales. Finally, the normalized decay rate of sensible heat flux is observed to be similar at all 


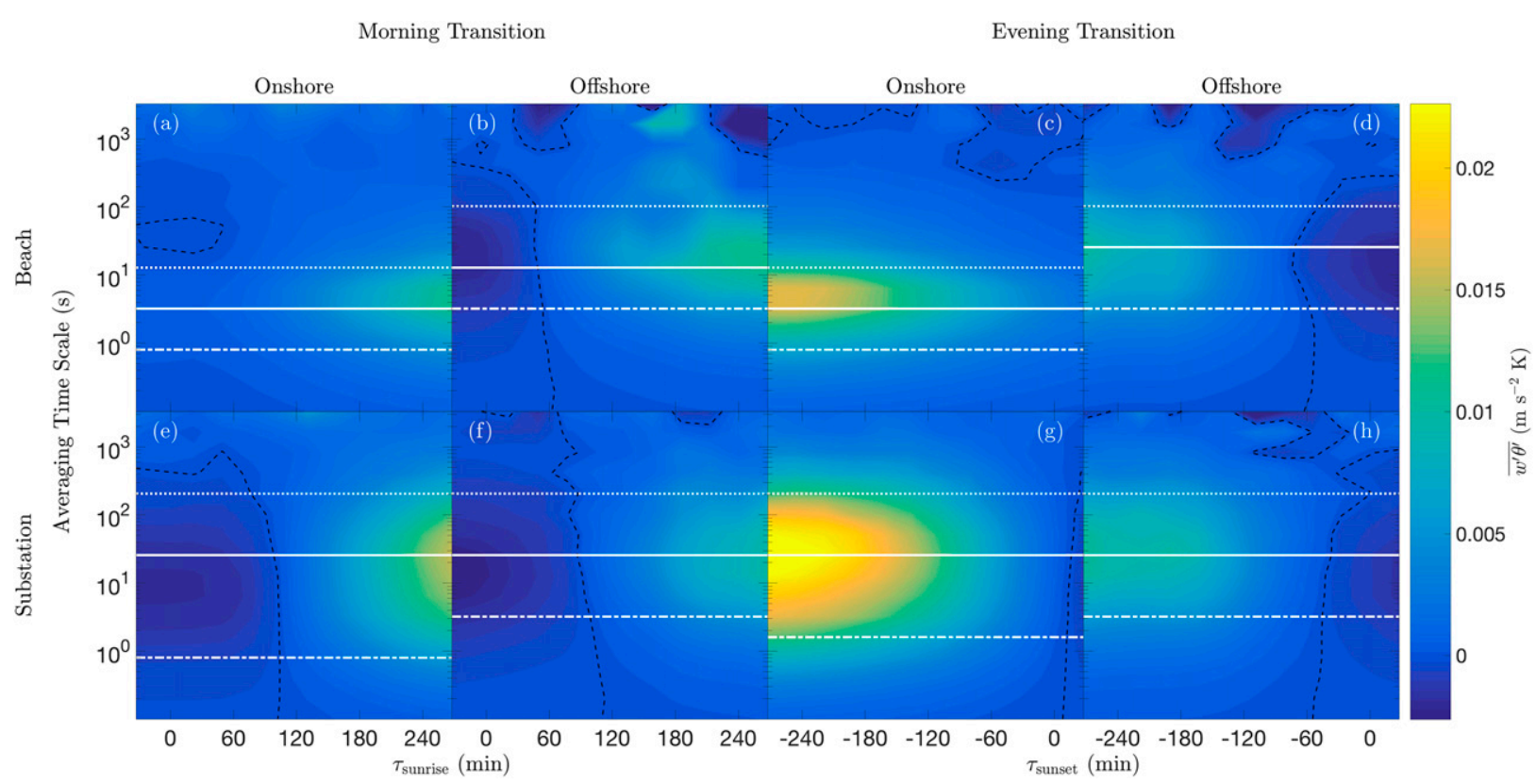

FIG. 9. MRFD cospectra of the kinematic sensible heat flux at the Beach and Substation sites for the onshore and offshore flow regimes through the MT and ET. The cospectra fluctuation time scales are indicated along the ordinate; the time relative to sunrise or sunset is indicated along the abscissa, and the color shading indicates the magnitude of the fluctuations associated with the given fluctuation scale and temporal location. The horizontal white lines indicate the large (top line), peak (middle line), and small (bottom line) time-scale fluctuations that are shown as time series in Fig. 10. The dashed black line is the zero-flux contour.

scales. The heat flux begins to slowly decay in the early afternoon, reaches a quasi-linear phase in the late afternoon, and then has a decreasing decay rate into the evening. We suggest that the trend at all scales could be fit accurately with the complementary error function as described in Nadeau et al. (2011).

\section{2) TKE Evolution}

The composite time series of turbulence kinetic energy, defined as $\bar{e}=(1 / 2)\left(\overline{u^{2}}+\overline{v^{2}}+\overline{w^{\prime 2}}\right)$, is given in Fig. 11. Typically, through the MT, $\bar{e}$ increases in response to increased surface heating and then decreases through the ET because of decreased surface heating. For the Beach onshore regime, the behavior is unique because $\bar{e}$ varies little in response to solar forcing and covaries much more closely with wind speed. Early in the MT, $\bar{e} \approx 1.5 \mathrm{~m}^{2} \mathrm{~s}^{-2}$ and then decreases later in the MT, in agreement with the observed decrease in wind speed (Fig. 5). Similarly, through the ET, $\bar{e}$ reaches a minimum $\approx 120$ min prior to sunset and then increases later into the evening, after the solar forcing has been cut off and an increase in wind speed is observed (Fig. 5). Nilsson et al. (2016b) used an idealized model to speculate that this could occur when shear production of $\bar{e}$ is much greater than buoyant production, which is the case here. It is unclear whether this would occur if the windbreak were not present; however, we speculate that, because of the high wind speed and relatively low surface heating, shear production of TKE is the dominant source of turbulence generation, regardless of the presence of the windbreak.

To understand the mechanisms contributing to the production and decay of turbulence through the MT and ET, the budget of TKE is considered. Because of instrumentation constraints, we must consider the simplified budget of TKE, which assumes horizontal homogeneity and no advection; the simplified budget is given by

$$
\underbrace{\frac{\partial \bar{e}}{\partial t}}_{\mathrm{I}}=-\underbrace{\overline{u^{\prime} w^{\prime}} \frac{\partial \bar{u}}{\partial z}}_{\mathrm{II}}+\underbrace{\frac{g}{\bar{\theta}} \overline{w^{\prime} \theta_{v}^{\prime}}}_{\mathrm{III}}-\underbrace{\frac{\partial \overline{w^{\prime} e^{\prime}}}{\partial z}}_{\mathrm{IV}}-\underbrace{\frac{\partial \overline{w^{\prime} P^{\prime} / \rho_{0}}}{\partial z}}_{\mathrm{V}}-\underbrace{\varepsilon,}_{\mathrm{VI}}
$$

where $P$ is pressure and $\rho_{0}$ is the ambient air density. Term I is the storage or tendency of TKE; II is shear production of TKE; III is buoyancy production of TKE; IV and V are turbulent and pressure transport of TKE, respectively; and $\varepsilon$ is the dissipation of TKE, which is always a sink.

Figure 12 illustrates composite budgets of TKE at Beach and Substation for the MT, ET and both flow 


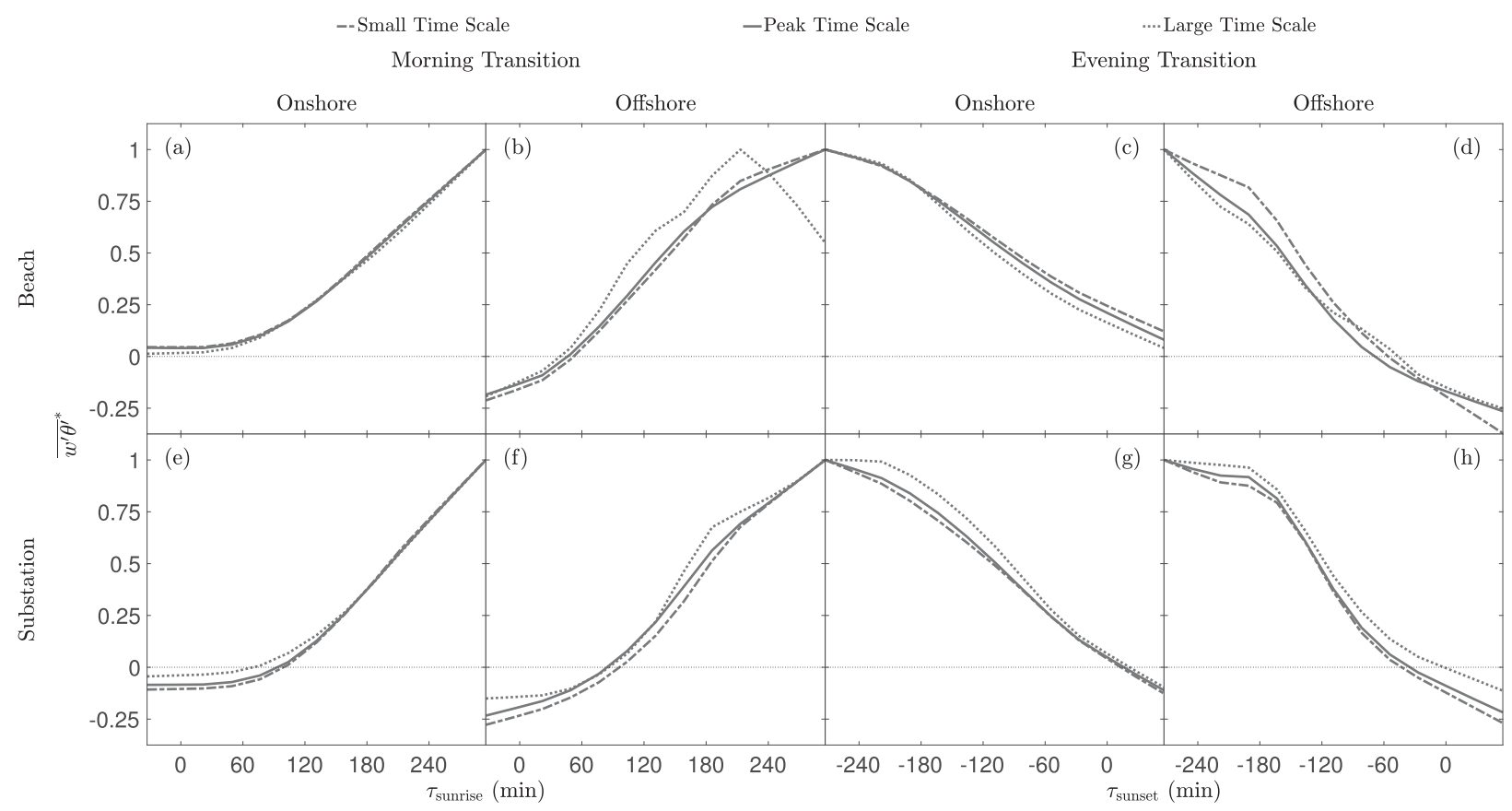

FIG. 10. Composite time series of the large, peak, and small time scales of the MRFD sensible heat flux cospectra (Fig. 9). Each time series has been normalized by its maximum value.

regimes. Term I was computed directly from the sonic anemometers; term II was computed from the sonic anemometer with the velocity gradient computed using forward differencing between the number- 40 cup anemometers at 10 and $20 \mathrm{~m}$; term III was computed from the sonic anemometers and HMP155 $T-\mathrm{RH}$ probe; following Nilsson et al. (2016a) and because of insufficient instrumentation, terms IV and $\mathrm{V}$ were computed as residuals and lumped together as a collective transport term, which includes the influence of terms IV and $\mathrm{V}$ along with all remaining residual influences including advection, subsidence, and instrument uncertainty.

The dissipation was estimated spectrally, following Nilsson et al. (2016a) as

$$
\varepsilon=\frac{2 \pi n}{\bar{u}}\left[\frac{3 n S_{w}(n)}{4 \alpha}\right]^{3 / 2}
$$

where $S_{w}$ is the power spectra of the vertical velocity, $n$ is frequency in $\mathrm{Hz}$, and $\alpha \approx 0.52$ is the Kolmogorov constant. Equation (4) was estimated by computing a linear fit of the pre-multiplied spectra over the inertial subrange in log-log space, where the slope is expected to $\approx-2 / 3$ (Kolmogorov 1968). The fit was forced to have a slope of $-2 / 3$ and then used with Eq. (4) to estimate the dissipation over 10-min intervals.
As expected from previous work (e.g., Nilsson et al. 2016a), in all cases, the TKE tendency is observed to be insignificant relative to the other terms. At the Beach site, the magnitude of the shear production and dissipation is observed to be much larger than those values observed at Substation, for both flow regimes and transitions (note the differing ordinate scales). Given that the velocity gradient is computed between the 10- and 20-m levels, it is likely that the shear production for the Beach onshore case is overestimated because of the presence of the windbreak disproportionately decelerating the $10-\mathrm{m}$ wind speed. Regardless, we speculate with confidence that shear production is the dominant mechanism for turbulence generation in the Beach onshore case.

At the Beach site, only the offshore ET case shows the expected decay in mechanical production. As discussed previously, for the onshore ET case, shear production actually increases later into the evening as the wind speed increases. The evening increase in shear production is sufficient to increase the level of TKE through the evening transition (Fig. 11). Finally, the turbulent transport, which is computed as a residual, is estimated to be a sink of TKE.

Because of relatively small sensible heat fluxes and the upstream windbreak, it was expected that shear production of TKE would be the dominant production term at Beach for the onshore regime, but it is somewhat 


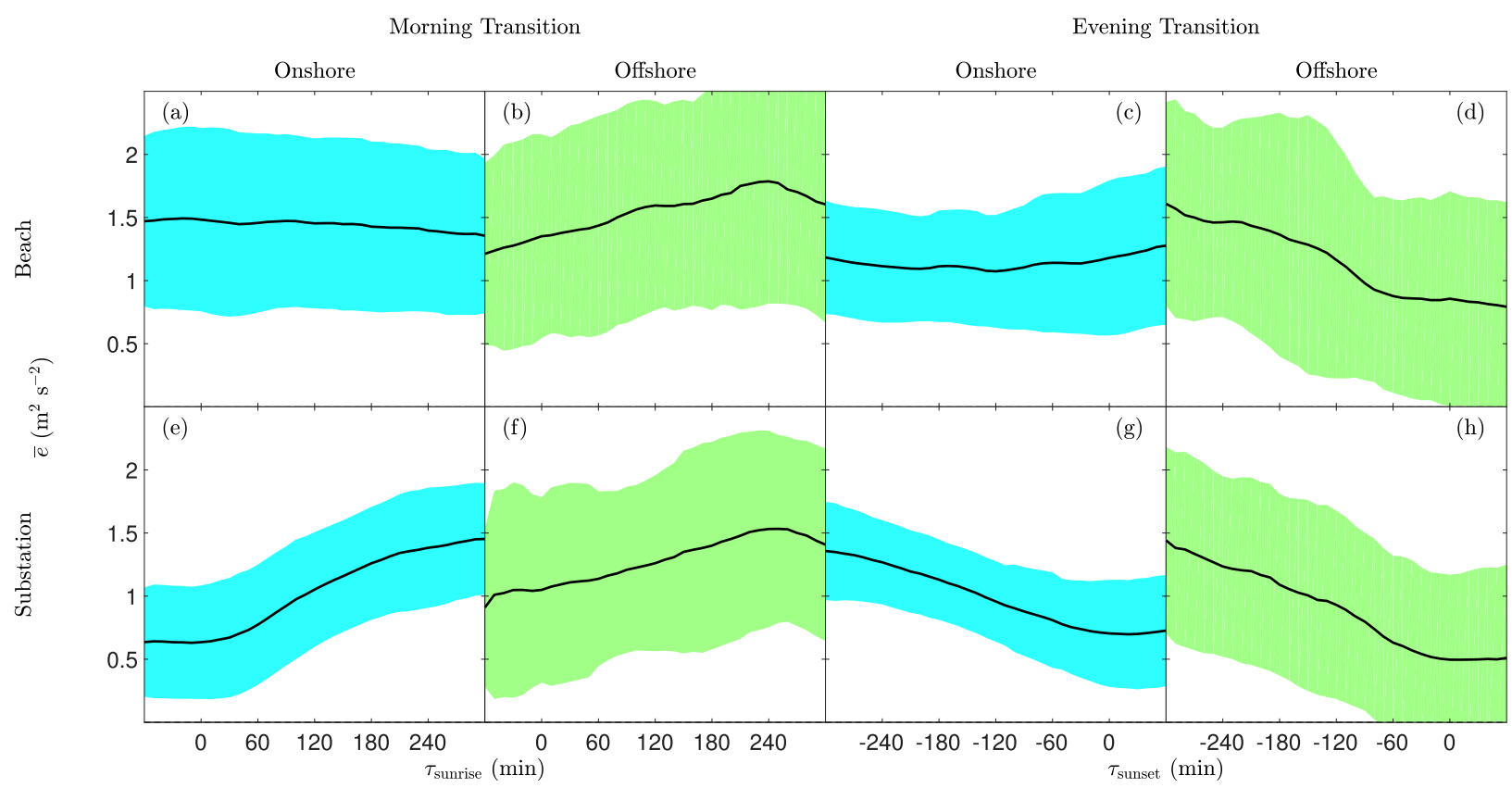

FIG. 11. Composite time series of the 10-m TKE through the MT and ET for both onshore $\left(40-\mathrm{m}\right.$ daily wind mode $\left.=90^{\circ} \pm 22.5^{\circ}\right)$ and offshore $\left(40-\mathrm{m}\right.$ daily wind mode $\left.=315^{\circ} \pm 22.5^{\circ}\right)$ flow regimes at the Beach and Substation locations. The shading indicates \pm 1 std dev of the composite TKE time series.

surprising that shear production is also dominant for the offshore regime. This is likely in part due to the large roughness of the mangrove, high wind speeds, and potential uncertainties in the vertical velocity gradient as a result of the heterogeneous terrain. For example, recirculations may develop on the leeward side of the mangrove forest, about $50 \mathrm{~m}$ upstream from the Substation tower. Presumably, the $20-\mathrm{m}$ wind speed is less influenced by such circulations.

At Substation, the production of TKE is much more balanced between buoyancy and shear. Shear production shows some diurnal influence as wind increases through the MT and decreases through the ET. The buoyant production is near-zero or slightly consumptive in the early morning and late evening and becomes nearly equal to shear production late in the MT and early in the ET. Unlike at the Beach site, the transport terms are estimated to act as a net source of TKE at all times.

Next, similar to the previous discussion of the sensible heat flux, the MRFD cospectra of the momentum flux are considered (Fig. 13). Similar to the sensible heat flux cospectra (Fig. 9), the scale disparity at Beach between onshore and offshore flow is observed. Surprisingly, the largest downward flux of momentum occurs during offshore flow at the Beach site, indicating that the mangrove upstream of the Beach tower effectively transports momentum into the canopy. Though not as pronounced, larger momentum fluxes are also observed for the offshore flow regime at Substation, indicating higher roughness for the Substation offshore fetch as well. Though not shown, this behavior is clearly evident from the increased velocity gradient observed in the velocity profiles for offshore flow.

For the Beach onshore regime, little diurnal influence is observed, indicating that shear production of turbulence is dominant. This is likely a result of shear induced by the windbreak as well as small sensible heat fluxes for the Beach onshore regime. For the other cases, as expected, larger fluctuations over a wider range of scales are observed during daylight hours. As was done for the sensible heat flux cospectra, time series of representative large, peak, and small time scales are shown in Fig. 14. For the Beach onshore case through the MT and ET, the small- and peak-scale fluctuations are quasi-constant through the diurnal cycle. Interestingly, for the ET, the peak and small scales increase late in the evening while the large timescale decays. As shown in Fig. 5, the increase in momentum flux at the peak and small scales roughly coincides with the increase in observed wind speed. Meanwhile, the decay in the large-scale momentum flux shows approximate agreement with the reduction of the sensible heat flux. This leads us to speculate that the mechanical production of turbulence is associated with smaller scales than the buoyant contribution for the onshore flow regime. 


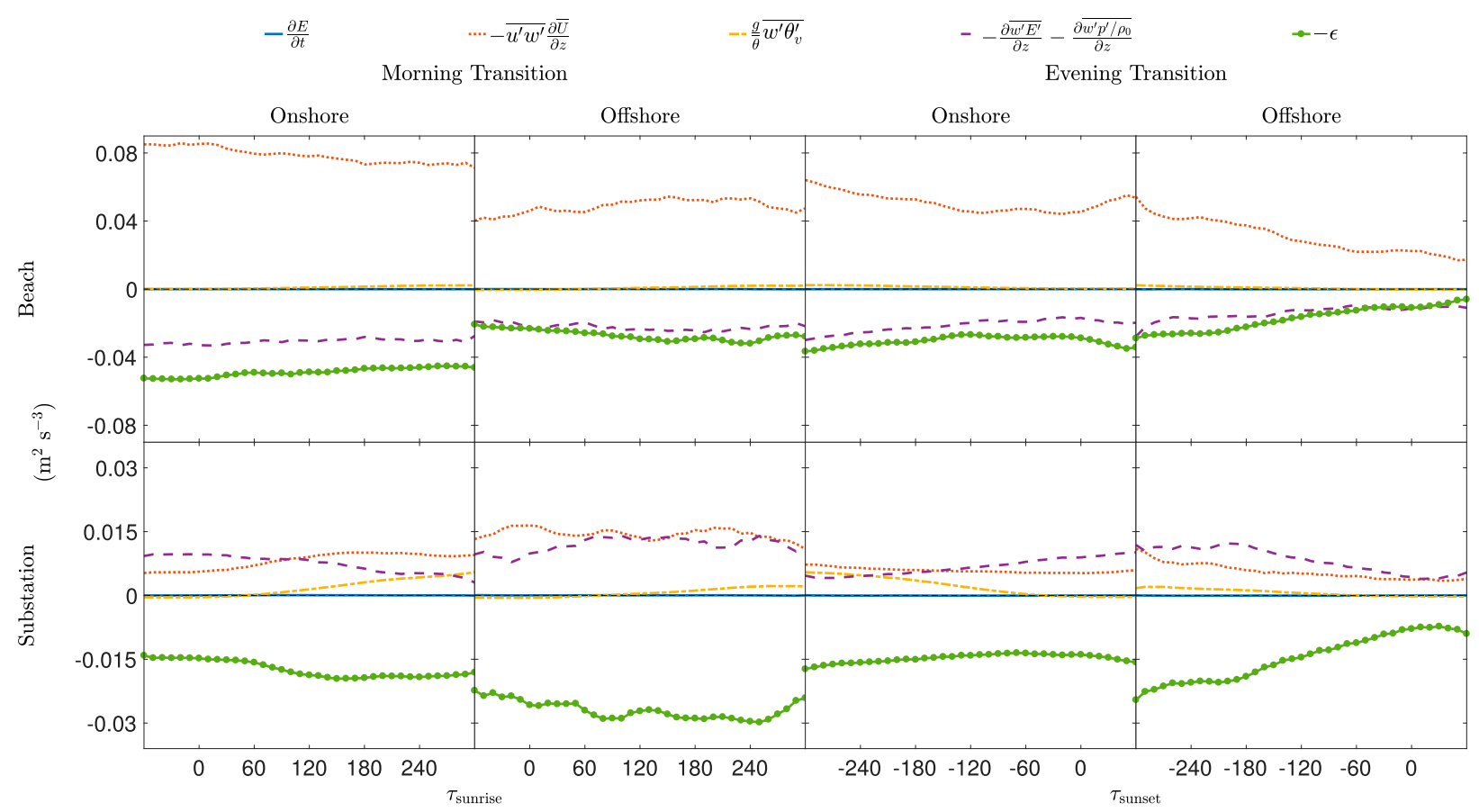

FIG. 12. Composite time series of the TKE budget terms [Eq. (3)]. Note that the ordinate scale differs between sites. Terms IV and V are lumped together and estimated as the residual of the budget. Terms are plotted such that values above (below) zero are a source (sink) of TKE.

\section{3) IDEALIZED TIMING AND STRUCTURE OF THE MORNING AND EVENING TRANSITIONS}

In the final section of the discussion, the previous analysis is used to construct an idealized schematic of the MT and ET over a coastal, tropical site (Fig. 15). Because the behavior of the Beach and Substation sites is quite similar for offshore flow conditions, we restrict the schematic to describing the difference between the Beach (coastal) and Substation (inland) sites for onshore flow conditions only. Starting with the coastal site, the sensible heat flux is near or slightly greater than zero but typically does not become negative. Once greater than zero, the growth and decay of the sensible heat flux is similar to the inland site but reaches only around $50 \%$ of the inland site's magnitude. The $40-\mathrm{m}$ wind speed at the coastal site is near constant throughout the diurnal cycle. There is a slight decrease in wind speed during the peak daylight hours that is likely caused by increased coupling with the surface. In other words, the 40-m level is initially greater than the height of the IBL but as mixing increases during peak daylight hours, the IBL deepens to $>40 \mathrm{~m}$, which decelerates the flow. The TKE is driven almost entirely by mechanical generation of turbulence. Therefore, TKE is near constant throughout the MT and ET and may decrease slightly during peak daylight hours. This is further illustrated by the scale-differentiated momentum fluxes. The peak- and large-scale momentum flux generally mirrors the mean wind speed while the large-scale momentum flux is highly influenced by the sensible heat flux.

At the inland site, the sensible heat flux evolution is much more typical of most midlatitude observational studies. The heat flux is negative from approximately $1 \mathrm{~h}$ before sunset to $1 \mathrm{~h}$ after sunrise. Coupled with the increase in sensible heat flux is the increase in daytime wind speed. This increase is the opposite of the daytime deceleration that occurs at the coastal site. We speculate that in the case of the inland site, the 40-m level is always within the IBL. As mixing increases, the IBL deepens and entrains fast moving air aloft. By conservation of momentum, the entrained air accelerates the flow within the IBL. The TKE evolution is closely tied to the sensible heat flux. This is mostly the case for the scale-differentiated momentum fluxes, but again, the large-scale momentum flux appears to be more influenced by the sensible heat flux while the peak- and small-scale momentum flux is more closely tied to wind speed. 


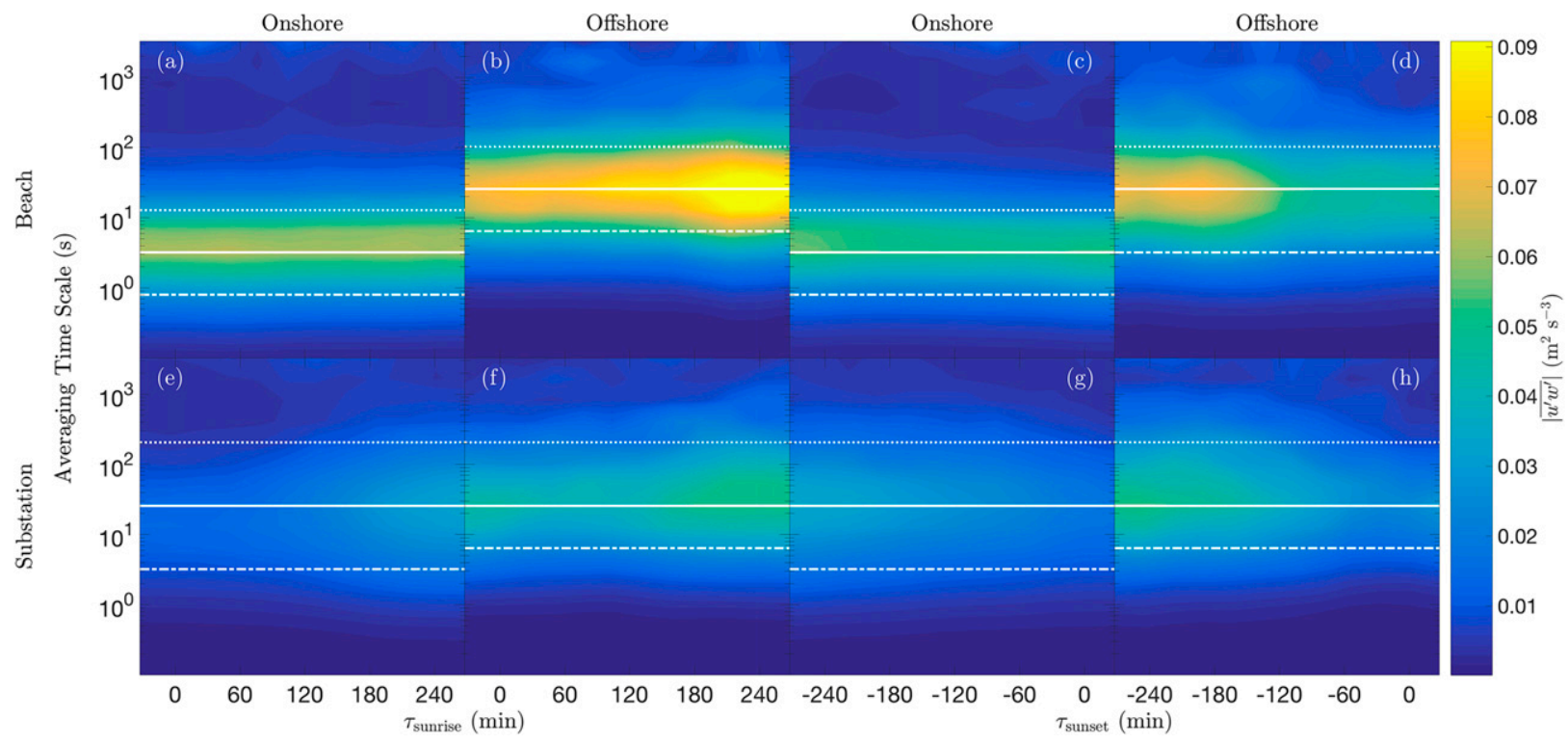

FIG. 13. As in Fig. 9, but for momentum flux.

\section{Conclusions}

An improved understanding of near-surface atmosphere dynamics through the MT and ET is critical both fundamentally and pragmatically. Here, we have used a 30-month dataset collected over heterogeneous terrain in Belize to study the morning and evening transitions.
Unlike most studies, we have made extensive use of composite time series with several hundred days of data to allow for a climatological examination of the ET and MT. The main conclusions are as follows:

1) There are two predominant wind regimes over Belize (Fig. 4): one directed easterly onshore that typically

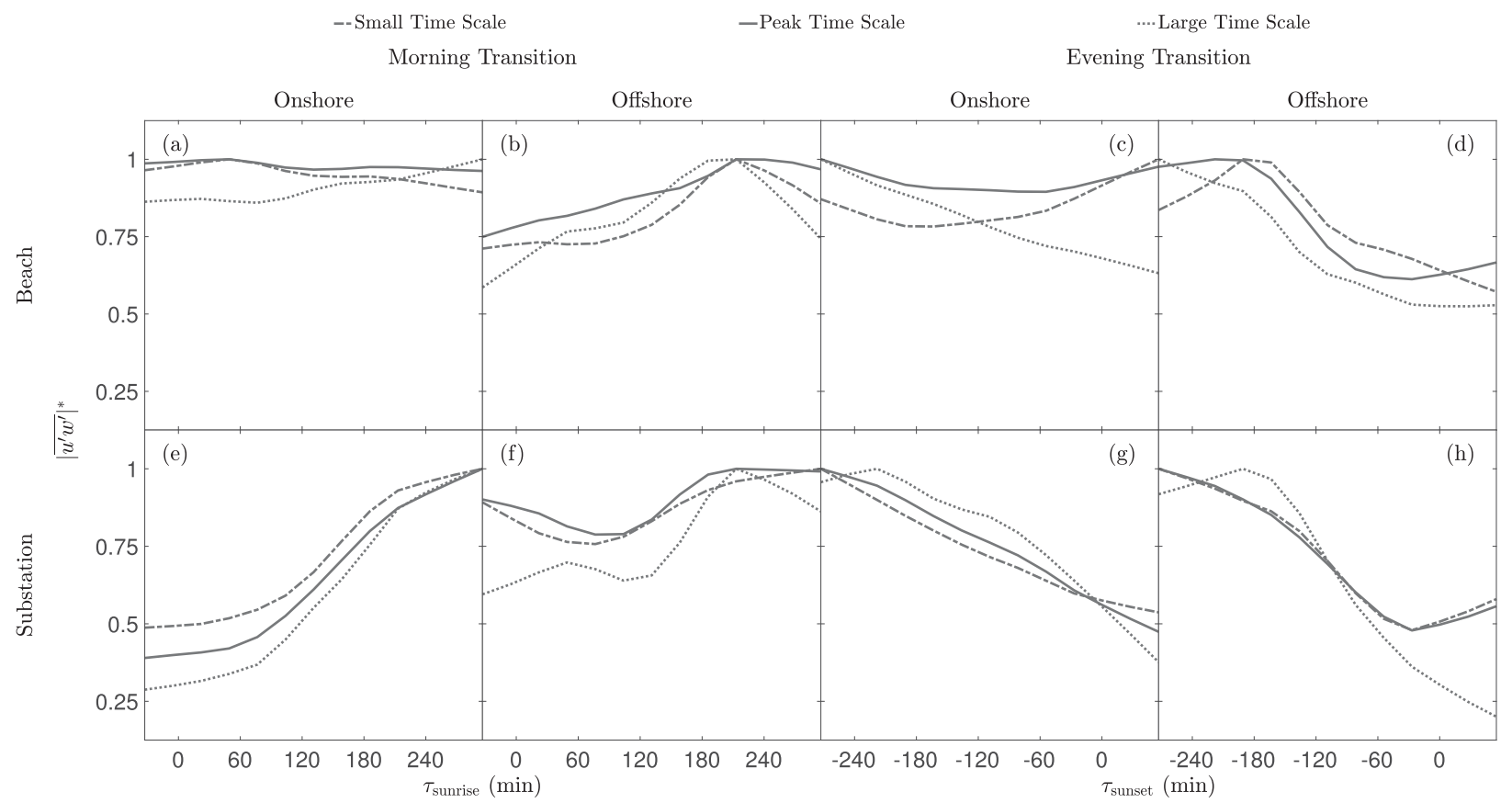

FIG. 14. As in Fig. 10, but for momentum flux. 


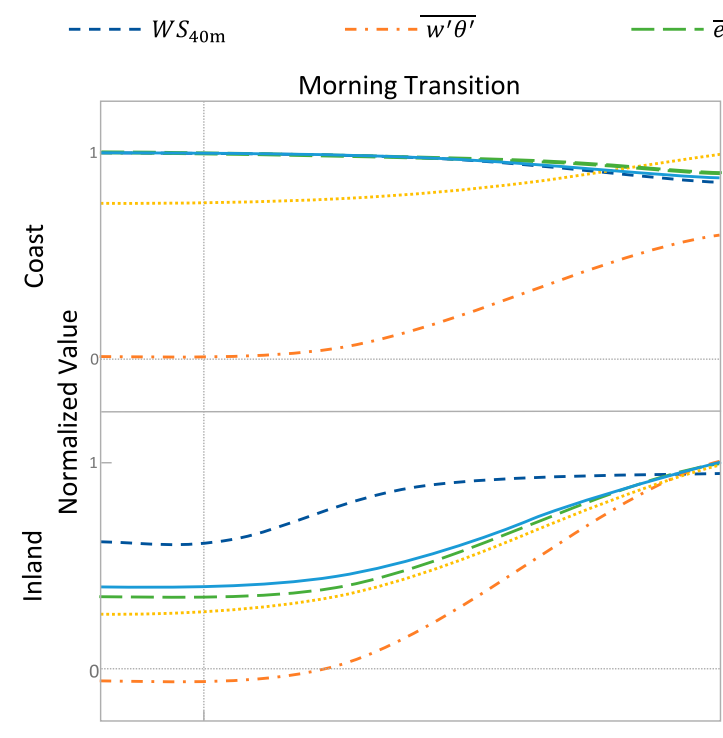

Sunrise

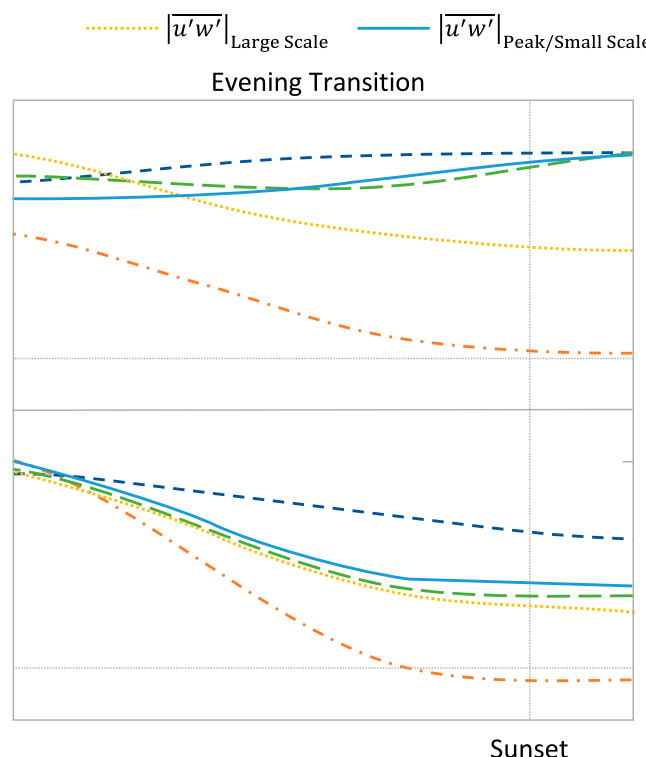

Sunset

FIG. 15. Idealized schematic of the morning and evening transition for onshore winds for both a coastal (the Beach) and inland (the Substation) site. The idealized time series are normalized by their maximum value that occurs at either location.

occurs during the wet season and another directed northwesterly offshore that typically occurs during the dry season. The mean wind speeds are much higher for the onshore regime.

2) Near-constant wind speeds are observed at the Beach tower during the onshore flow regime, with a slight deceleration during daylight hours likely due to the IBL deepening to depths $>40 \mathrm{~m}$. The $40-\mathrm{m}$ wind speed at the inland sites accelerates during daylight hours, presumably because of entrainment of highmomentum air parcels aloft (Figs. 5 and 6).

3) The inland wind deficit is approximately $4 \% \mathrm{~km}^{-1}$ during the onshore flow regime with the Beach tower observing higher wind speeds and less wind-direction scatter. For wind energy applications, constructing turbines near the coast is beneficial because the mean wind speeds are higher and the diurnal fluctuations are smaller.

4) The inland temperature gradient magnitude (Fig. 7) is much larger for onshore flow. The influence of the sea breeze appears to be much less than the synoptic forcing responsible for the seasonal wind patterns. However, there were occasional days during the offshore flow regime for which the diurnal sea breeze-land breeze evolution is identifiable (Fig. 4). The isolated events were mostly eliminated from the present study because of the criteria used to categorize days as being either onshore or offshore [section $3 \mathrm{a}(1)$ ].
5) The evolution of sensible heat flux (Fig. 8) for the offshore flow regime is very similar both inland and at the coast. In general, the diurnal duration of the positive sensible heat flux (heat transported away from the surface) is several hours longer than the duration of the unstable bulk temperature gradient, measured between $10 \mathrm{~m}$ and the top of the tower (50 $\mathrm{m}$ at Beach and $60 \mathrm{~m}$ at Substation). For onshore flow, we rarely observe rarely observe negative fluxes at the Beach site and the magnitude of the daytime flux is approximately half of that observed at the inland (Substation) site.

6) Multiresolution flux decomposition was used to study the spatial and temporal scales of sensible heat flux through the MT and ET. MRFD revealed a scale disparity between the onshore and offshore regimes at the Beach site (Figs. 9 and 10). The onshore flow at the Beach site was associated with smaller time scales, likely because of the flux footprint being mostly over the relatively "smooth" ocean. In general through the MT, the heat flux crosses zero first at larger scales. Contrarily, through the ET, the sensible heat flux becomes negative at smaller time scales first. Save for the lag in the crossover of the differing scales, the interscale variation of the heat flux evolution is quite small for all conditions considered.

7) The turbulence kinetic energy (TKE) evolution and budgets were examined in Figs. 11 and 12. For offshore flow, the behavior between the sites is quite 
similar, with both mechanical and thermal production of TKE being important. For onshore flow at Beach, buoyant production of TKE is much smaller than the other measured terms. The TKE evolution is generated almost entirely mechanically. This behavior allows for the situation hypothesized in Nilsson et al. (2016b) where the TKE increases through the ET as a result of increased wind speed.

8) MRFD was also used to study the temporal and spatial scales of the momentum flux through the MT and ET (Figs. 13 and 14). Again, the scale disparity at the Beach site for the onshore and offshore regimes is evident. Unlike the sensible heat flux, the interscale variation of the momentum flux evolution is much larger. At the Beach site, it is observed that the largescale momentum flux is likely more influenced by buoyant production because it resembles the evolution of the sensible heat flux. The small and peak scales appear to be more influenced by mechanical production and more closely resemble the wind speed evolution. This is particularly evident in Fig. 14c.

9) An idealized schematic of the MT and ET over coastal, tropical terrain was presented in Fig. 15. The schematic illustrates the evolution of wind speed, sensible heat flux, TKE, and scale-differentiated momentum flux through the MT and ET for a coastal and inland site. We hypothesize that this behavior may be generalizable to sites similar to the shrimp farm where this study was conducted.

Acknowledgments. We thank Washakie Renewable Energy for their generous support and funding for the project. We also thank all of the staff at the Paradise Shrimp Farm, especially Hank Bauman and Patrick Flores. Patrick quickly responded to all of our requests, and Hank was frequently out checking and repairing instrumentation for us when we were unable to make the trip. The data availability would be much worse if it were not for both of their efforts. This work was prepared in part by LLNL under Contract DE-AC52-07NA27344.

\section{REFERENCES}

Acevedo, O. C., and D. R. Fitzjarrald, 2001: The early evening surface-layer transition: Temporal and spatial variability. J. Atmos. Sci., 58, 2650-2667, https://doi.org/10.1175/ 1520-0469(2001)058<2650:TEESLT > 2.0.CO; 2 .

Angevine, W. M., 2008: Transitional, entraining, cloudy, and coastal boundary layers. Acta Geophys., 56, 2-20, https:// doi.org/10.2478/s11600-007-0035-1.

, H. K. Baltink, and F. C. Bosveld, 2001: Observations of the morning transition of the convective boundary layer. Bound.Layer Meteor., 101, 209-227, https://doi.org/10.1023/A: 1019264716195.
Bange, J., T. Spieß, and A. van den Kroonenberg, 2007: Characteristics of the early-morning shallow convective boundary layer from Helipod flights during STINHO-2. Theor. Appl. Climatol., 90, 113-126, https://doi.org/10.1007/s00704-006-0272-2.

Basu, S., J.-F. Vinuesa, and A. Swift, 2008: Dynamic LES modeling of a diurnal cycle. J. Appl. Meteor. Climatol., 47, 1156-1174, https://doi.org/10.1175/2007JAMC1677.1.

Beare, R. J., 2008: The role of shear in the morning transition boundary layer. Bound.-Layer Meteor., 129, 395-410, https:// doi.org/10.1007/s10546-008-9324-8.

Blay-Carreras, E., E. R. Pardyjak, D. Pino, D. C. Alexander, F. Lohou, and M. Lothon, 2014: Countergradient heat flux observations during the evening transition period. Atmos. Chem. Phys., 14, 9077-9085, https://doi.org/10.5194/acp-14-9077-2014.

Brazel, A. J., H. J. S. Fernando, J. C. R. Hunt, N. Selover, B. C. Hedquist, and E. Pardyjak, 2005: Evening transition observations in Phoenix, Arizona. J. Appl. Meteor., 44, 99-112, https://doi.org/10.1175/JAM-2180.1.

Crosman, E. T., and J. D. Horel, 2010: Sea and lake breezes: A review of numerical studies. Bound.-Layer Meteor., 137, 1-29, https://doi.org/10.1007/s10546-010-9517-9.

Cuxart, J., and Coauthors, 2016: Estimation of the advection effects induced by surface heterogeneities in the surface energy budget. Atmos. Chem. Phys., 16, 9489-9504, https://doi.org/ 10.5194/acp-16-9489-2016.

Fernando, H. J. S., and Coauthors, 2015: The MATERHORN: Unraveling the intricacies of mountain weather. Bull. Amer. Meteor. Soc., 96, 1945-1967, https://doi.org/10.1175/BAMS-D-13-00131.1.

Garratt, J. R., 1990: The internal boundary layer-A review. Bound.Layer Meteor., 50,171-203, https://doi.org/10.1007/BF00120524.

_ 1994: Review: The atmospheric boundary layer. Earth-Sci. Rev., 37, 89-134, https://doi.org/10.1016/0012-8252(94)90026-4.

Goulart, A. G., B. E. J. Bodmann, M. T. M. B. de Vilhena, P. M. M. Soares, and D. M. Moreira, 2011: On the time evolution of the turbulent kinetic energy spectrum for decaying turbulence in the convective boundary layer. Bound.-Layer Meteor., 138, 61-75, https://doi.org/10.1007/s10546-010-9546-4.

Graf, A., A. van de Boer, A. Moene, and H. Vereecken, 2014: Intercomparison of methods for the simultaneous estimation of zero-plane displacement and aerodynamic roughness length from single-level eddy-covariance data. Bound.-Layer Meteor., 151, 373-387, https://doi.org/10.1007/s10546-013-9905-z.

Grant, A. L. M., 1997: An observational study of the evening transition boundary-layer. Quart. J. Roy. Meteor. Soc., 123, 657-677, https://doi.org/10.1002/qj.49712353907.

Holtslag, A. A. M., and Coauthors, 2013: Stable atmospheric boundary layers and diurnal cycles: Challenges for weather and climate models. Bull. Amer. Meteor. Soc., 94, 1691-1706, https://doi.org/10.1175/BAMS-D-11-00187.1.

Howell, J. F., and L. Mahrt, 1997: Multiresolution flux decomposition. Bound.-Layer Meteor., 83, 117-137, https://doi.org/10.1023/ A:1000210427798.

Hsieh, C.-I., G. Katul, and T.-W. Chi, 2000: An approximate analytical model for footprint estimation of scalar fluxes in thermally stratified atmospheric flows. Adv. Water Resour., 23, 765-772, https://doi.org/10.1016/S0309-1708(99)00042-1.

Jensen, D. D., D. F. Nadeau, S. W. Hoch, and E. R. Pardyjak, 2016: Observations of near-surface heat-flux and temperature profiles through the early evening transition over contrasting surfaces. Bound.-Layer Meteor., 159, 567-587, https://doi.org/ 10.1007/s10546-015-0067-z.

Katul, G. G., and M. B. Parlange, 1995: The spatial structure of turbulence at production wavenumbers using orthonormal 
wavelets. Bound.-Layer Meteor., 75, 81-108, https://doi.org/ 10.1007/BF00721045.

Kolmogorov, A. N., 1968: Local structure of turbulence in an incompressible viscous fluid at very high Reynolds numbers. Phys.-Usp., 10, 734-746, https://doi.org/10.1070/PU1968v010n06ABEH003710.

Kumar, V., J. Kleissl, C. Meneveau, and M. B. Parlange, 2006: Largeeddy simulation of a diurnal cycle of the atmospheric boundary layer: Atmospheric stability and scaling issues. Water Resour. Res., 42, W06D09, https://doi.org/10.1029/2005WR004651.

Lampert, A., and Coauthors, 2016: A study of local turbulence and anisotropy during the afternoon and evening transition with an unmanned aerial system and mesoscale simulation. Atmos. Chem. Phys., 16, 8009-8021, https://doi.org/10.5194/acp-16-8009-2016.

Lapworth, A., 2006: The morning transition of the nocturnal boundary layer. Bound.-Layer Meteor., 119, 501-526, https:// doi.org/10.1007/s10546-005-9046-0.

Lenschow, D. H., B. B. Stankov, and L. Mahrt, 1979: The rapid morning boundary-layer transition. J. Atmos. Sci., 36, 21082124, https://doi.org/10.1175/1520-0469(1979)036<2108: TRMBLT $>2.0 . \mathrm{CO} ; 2$.

Lothon, M., and Coauthors, 2014: The BLLAST field experiment: Boundary-Layer Late Afternoon and Sunset Turbulence. Atmos. Chem. Phys., 14, 10 931-10 960, https://doi.org/10.5194/ acp-14-10931-2014.

Manoj, M. G., P. C. S. Devara, and S. Taraphdar, 2013: Lidar investigation of tropical nocturnal boundary layer aerosols and cloud macrophysics. Atmos. Res., 132-133, 65-75, https://doi.org/ 10.1016/j.atmosres.2013.05.007.

Nadeau, D. F., E. R. Pardyjak, C. W. Higgins, H. J. S. Fernando, and M. B. Parlange, 2011: A simple model for the afternoon and early evening decay of convective turbulence over different land surfaces. Bound.-Layer Meteor., 141, 301-324, https://doi.org/10.1007/s10546-011-9645-x.

National Meteorological Service of Belize, 2016: The Climate of Belize. Climate Summary, http://hydromet.gov.bz/climatology/ climate-summary.

Nieuwstadt, F. T. M., and R. A. Brost, 1986: The decay of convective turbulence. J. Atmos. Sci., 43, 532-546, https://doi.org/ 10.1175/1520-0469(1986)043<0532:TDOCT > 2.0.CO;2.

Nilsson, E., F. Lohou, M. Lothon, E. Pardyjak, L. Mahrt, and C. Darbieu, 2016a: Turbulence kinetic energy budget during the afternoon transition-Part 1: Observed surface TKE budget and boundary layer description for 10 intensive observation period days. Atmos. Chem. Phys., 16, 8849-8872, https://doi.org/ 10.5194/acp-16-8849-2016.

-, M. Lothon, F. Lohou, E. Pardyjak, O. Hartogensis, and C. Darbieu, 2016b: Turbulence kinetic energy during the afternoon transition-Part 2: A simple TKE model. Atmos. Chem. Phys., 16, 8873-8898, https://doi.org/10.5194/acp-16-8873-2016.
Parameswaran, K., K. Rajeev, and K. Sen Gupta, 1997: An observational study of night time aerosol concentrations in the lower atmosphere at a tropical coastal station. J. Atmos. Sol.-Terr. Phys., 59, 1727-1737, https://doi.org/ 10.1016/S1364-6826(97)00013-8.

Pino, D., H. J. J. Jonker, J. V.-G. de Arellano, and A. Dosio, 2006: Role of shear and the inversion strength during sunset turbulence over land: Characteristic length scales. Bound.-Layer Meteor., 121, 537-556, https://doi.org/10.1007/s10546-006-9080-6.

Rizza, U., M. M. Miglietta, G. A. Degrazia, O. C. Acevedo, and E. P. Marques Filho, 2013: Sunset decay of the convective turbulence with large-eddy simulation under realistic conditions. Physica A, 392, 4481-4490, https://doi.org/10.1016/j.physa.2013.05.009.

Robinson, S. M., 1962: Computing wind profile parameters. J. Atmos. Sci., 19, 189-190, https://doi.org/10.1175/1520-0469(1962)019<0189: CWPP $>2.0 . \mathrm{CO} ; 2$.

Roth, M., 2007: Review of urban climate research in (sub)tropical regions. Int. J. Climatol., 27, 1859-1873, https://doi.org/10.1002/joc.1591.

Sáenz, F., and A. M. Durán-Quesada, 2015: A climatology of low level wind regimes over central America using a weather type classification approach. Front. Earth Sci., 3, https://doi.org/ 10.3389/feart.2015.00015.

Sorbjan, Z., 1997: Decay of convective turbulence revisited. Bound.-Layer Meteor., 82, 503-517, https://doi.org/10.1023/A: 1000231524314.

- 2007: A numerical study of daily transitions in the convective boundary layer. Bound.-Layer Meteor., 123, 365-383, https:// doi.org/10.1007/s10546-006-9147-4.

Steeneveld, G.-J., 2014: Current challenges in understanding and forecasting stable boundary layers over land and ice. Front. Environ. Sci., 2, https://doi.org/10.3389/fenvs.2014.00041.

Stull, R. B., 1988: An Introduction to Boundary Layer Meteorology. Kluwer Academic, 666 pp., https://doi.org/10.1007/978-94-009-3027-8.

Svensson, G., and Coauthors, 2011: Evaluation of the diurnal cycle in the atmospheric boundary layer over land as represented by a variety of single-column models: The second GABLS experiment. Bound.-Layer Meteor., 140, 177-206, https://doi.org/ 10.1007/s10546-011-9611-7.

Vickers, D., and L. Mahrt, 2003: The cospectral gap and turbulent flux calculations. J. Atmos. Oceanic Technol., 20, 660-672, https:// doi.org/10.1175/1520-0426(2003)20<660:TCGATF >2.0.CO;2.

Wang, D., J. C. McWilliams, and W. G. Large, 1998: Large-eddy simulation of the diurnal cycle of deep equatorial turbulence. J. Phys. Oceanogr., 28, 129-148, https://doi.org/10.1175/ 1520-0485(1998)028<0129:LESOTD > 2.0.CO;2.

Zhang, D.-L., and W.-Z. Zheng, 2004: Diurnal cycles of surface winds and temperatures as simulated by five boundary layer parameterizations. J. Appl. Meteor., 43, 157-169, https://doi.org/ 10.1175/1520-0450(2004)043<0157:DCOSWA > 2.0.CO;2. 